\title{
ICOS + Tregs: A Functional Subset of Tregs in Immune Diseases
}

\author{
Dan-Yang Li and Xian-Zhi Xiong* \\ Department of Respiratory and Critical Care Medicine, NHC Key Laboratory of Pulmonary Diseases, Union Hospital, Tongji \\ Medical College, Huazhong University of Science and Technology, Wuhan, China
}

Recent studies have reported the pathological effect of ICOS ${ }^{+} \mathrm{T}$ cells, but ICOS signals also widely participate in anti-inflammatory responses, particularly $\mathrm{ICOS}^{+}$regulatory $\mathrm{T}$ (Treg) cells. The ICOS signaling pathway endows Tregs with increased generation, proliferation, and survival abilities. Furthermore, there is enough evidence to suggest a superior capacity of ICOS ${ }^{+}$Tregs, which is partly attributable to IL-10 induced by ICOS, yet the associated mechanism needs further investigation. In this review, we discuss the complicated role of ICOS ${ }^{+}$Tregs in several classical autoimmune diseases, allergic diseases, and cancers and investigate the related therapeutic applications in these diseases. Moreover, we identify ICOS as a potential biomarker for disease treatment and prognostic prediction. In addition, we believe that anti-ICOS/ICOSL monoclonal antibodies exhibit excellent clinical application potential. A thorough understanding of the effect of ICOS ${ }^{+}$Tregs and the holistic role of ICOS toward the immune system will help to improve the therapeutic schedule of diseases.

Keywords: ICOS, Treg cells, autoimmune disease, neoplasm, immunotherapy

\section{INTRODUCTION}

Inducible T-cell costimulator (ICOS) is a homodimeric protein with a molecular weight of approximately $55 \sim 60 \mathrm{kD}$ that was originally discovered on the surface of $\mathrm{T}$ cells upon T-cell receptor (TCR) stimulation in 1999 (1). As the third member of the CD28 super family, the structure and function of ICOS have many similarities with CD28 despite some differences, with the major difference being that ICOS cannot be constitutively expressed on resting T cells. Exhibiting no binding with B7-1/B7-2, ICOS has a unique ligand, ICOSL, which is expressed on the surface of many antigen presenting cells (APCs), such as B cells, dendritic cells (DCs), macrophages, and other cell types from non-lymphoid tissue, including fibroblasts, endothelial cells and epithelial cells (2). Intriguingly, ICOSL has also been detected on a small subset of T cells, accounting for $5 \%$ of $\mathrm{CD}^{+} \mathrm{T}$ cells, although the details regarding this population remain unknown (3). Recently, many researchers have investigated the distribution of ICOS on T cells, and the expression of ICOS on Th1, Th2, Th17, T follicular helper (Tfh) cells, T follicular regulatory (Tfr) cells, Tregs, type 1 regulatory $\mathrm{T}(\mathrm{Tr} 1)$ cells, and innate lymphoid cells (ILCs) have been successively reported, showing its indispensable role in immune responses (4-6). Taking into consideration the complexity of ICOS distribution on T cell subsets and its diverse effect toward each subset, the role of ICOS in various diseases can hardly be summarized in one word. The overexpression of ICOS could either lead to Th1 or Th2 dependent immune responses, among which regulatory $\mathrm{T}$ cells are an important counterbalance in the inflammatory state (7). 
First in mice (8) and then in humans (9), researchers discovered a correlation between the highest level of ICOS on $\mathrm{CD}^{+} \mathrm{T}$ cells with the generation of the anti-inflammatory cytokine IL-10, demonstrating the central role of ICOS in the differentiation and function of $\mathrm{FOXP}^{+}$Tregs. Subsequently, numerous studies have been published to elucidate the role of ICOS $^{+}$Tregs in homeostasis and different disease conditions. Herein, we describe the phenotype and function of $\mathrm{ICOS}^{+}$ Tregs and summarize ICOS-associated signaling pathways of Tregs and their relationship with two important cytokines, IL2 and IL-10. We also compare ICOS signal transduction with CD28- and CTLA-4-mediated signaling pathways, and describe their synergetic effect on anti-inflammation. In addition, we highlight the crucial role of ICOS $^{+}$Tregs in various immune diseases and outline its diagnostic and therapeutic effect in autoimmune responses.

\section{ICOS AND Tregs}

\section{Origin and Phenotype of ICOS ${ }^{+}$Tregs}

In homeostasis, $\mathrm{ICOS}^{+} \mathrm{T}$ cells only account for a small subset of $\mathrm{CD}^{+} \mathrm{T}$ cells in peripheral blood, while they are particularly enriched in $\mathrm{FOXP}^{+}$Tregs, accounting for approximately $20 \%$ of Tregs, with most ICOS ${ }^{+}$Tregs being $\mathrm{CXCR}^{+}{ }^{+}$or $\mathrm{CXCR}^{-}{ }^{-} \mathrm{CCR}^{+}{ }^{+} \mathrm{CCR} 10^{-}$, defined as Th1-like or Th17-like Tregs, respectively (10). The much higher proportion of $\mathrm{CD}^{+}{ }^{-\mathrm{COS}^{+}}$Tregs among $\mathrm{CD}^{+}$Tregs than that of $\mathrm{CD}^{+}{ }^{+} \mathrm{COS}^{+} \mathrm{T}$ cells among $\mathrm{CD} 4^{+} \mathrm{T}$ cells begs a question: where do these $\mathrm{ICOS}^{+}$Tregs come from? During the development of thymocytes, only $\mathrm{T}$ cells with high-affinity TCR evolve into Tregs, and combined with the consideration that the recognition of antigens with TCR is a prerequisite for the induced expression of ICOS, it was supposed that the increased proportion of ICOS in Tregs was partly induced by these self-antigens presented by medullary thymic epithelial cells (mTECs). This opinion has been put forward by Ito et al. (2008), who observed that both $\mathrm{ICOS}^{+}$and $\mathrm{ICOS}^{-}$Tregs existed in both newborn thymus and cord blood, and $50 \%$ of the $\mathrm{ICOS}^{+}$Tregs from cord blood expressed CD31, suggesting it contains recent thymic emigrants (9). In addition, mTECs can induce IL-2 overproduction by $\mathrm{CD} 4^{+} \mathrm{CD} 25^{-} \mathrm{T}$ cells via ICOSL to promote Treg proliferation, providing additional evidence for the existence of ICOS $^{+}$Tregs in the thymus (11). However, almost all of these $\mathrm{ICOS}^{+}$Tregs in adult blood were $\mathrm{CD} 45 \mathrm{RO}^{+}$, contrasting with the phenotype of $\mathrm{ICOS}^{-}$Tregs, which still included some CD45RA ${ }^{+}$Tregs, and $\mathrm{ICOS}^{+}$Tregs in cord blood, which expressed high levels of CD45RA (9). This phenomenon suggested that most of the ICOS $^{+}$Tregs in adult blood are actually effector/memory Treg cells. Similarly, although ICOS is expressed in small amounts in $\mathrm{CD} 44^{\text {lo }} \mathrm{CD} 62 \mathrm{~L}^{\text {hi }}$ cTregs, ICOS is highly expressed in murine splenic CD44 ${ }^{\text {hi CD62L }}{ }^{\text {lo }}$ eTregs (12). Most of these eTregs are Helios-positive, indicating they are mostly derived from the thymus (12). Moreover, Nicolas and colleagues have observed the expansion of $\mathrm{ICOS}^{+}$Tregs from the pool of naturally occurring Tregs (nTregs) after 2,4-dinitrofluorobenzene (DNFB) sensitization in mice and ICOS $^{+}$Tregs being generated from
$\mathrm{ICOS}^{-}$precursors (13). In addition, using T cell adoptive transfer experiments, they did not observe a generation of adaptive Tregs (aTregs) with ICOS expression from FOXP3 ${ }^{-} \mathrm{T}$ cells after DNFB sensitization (13). However, by eliminating thymusderived Treg (tTreg, also known as nTreg) development using Rag1 ${ }^{-/}$mice, Ashley et al. have demonstrated that ICOS deficiency can reduce the accumulation of peripherally induced Tregs (pTregs, also known as aTregs) in the large intestine, indicating an important role of ICOS for the generation of pTregs under steady state conditions (14). Therefore, ICOS ${ }^{+}$Tregs can be generated from both the thymus and peripheral tissues, which can be expanded rapidly or transformed from ICOS $^{-}$nTregs after antigen stimulation. Additionally, we suspect that the higher ICOS expression levels in Tregs than in other $\mathrm{CD} 4^{+} \mathrm{T}$ cell subsets could be beneficial for the maintenance of immune homeostasis, as the superior suppressive ability of ICOS $^{+}$Tregs could make them more efficient and capable of preventing the human body from producing overactive inflammatory responses to daily lowdose harmless antigenic stimulation.

Recently, various studies have investigated the phenotype of $\mathrm{ICOS}^{+}$Tregs in diverse diseases or in the steady state. In general, Tregs with ICOS expression also coexpress many immunosuppressive receptors, such as CTLA-4, PD-1, TIGIT, and Lag3, and exhibit a higher secretion of IL-10, providing them with superior suppressive potential $(13,15)$. However, it is not clear if ICOS expression or signaling accounts for these observations. The co-expression of these molecules may be a reflection of the fact that they are both highly expressed by eTregs. ICOS, as a co-stimulatory molecule, does not have a direct inhibitory function per se. Whether the ICOS signaling could influence the expression of other co-inhibitory molecules needs further exploration, and some of the relationships between ICOS and CTLA-4 or IL-10 are discussed below (in section "ICOS and CTLA-4" and section "The Role of ICOS Signaling in Tregs," respectively).

Furthermore, $\mathrm{ICOS}^{+}$Tregs also upregulate many genes associated with TCR stimulation and appear to be more proliferative. Some transcription factors that are usually associated with $\mathrm{T}$ helper cell differentiation have been observed to participate in the biology of eTregs and to be associate with ICOS expression. For example, B lymphocyte induced maturation protein 1 (Blimp1), which regulates eTregs activation and tissue homeostasis, is required for IL-10 production and ICOS expression (16). Interferon regulatory factor 4 (IRF4), one molecule expressed in both Th2 cells and Tregs, was demonstrated to be essential for Tregs to suppress Th2 responses and was further shown to be required in type 1 inflammatory conditions due to its role in the effector Treg differentiation $(16,17)$. Irf4 ${ }^{-/}$Tregs show impaired CD62L downregulation and loss ICOS expression in the mixed chimeric mice generated with WT and Irf4-/- bone morrow (16). Furthermore, JunB, an important AP-1 factor, has also been observed to promote ICOS expression in basic leucine zipper transcription factor ATF-like (BATF)-dependent and BATF-independent manners in murine eTregs (18). By chromatin immunoprecipitation (ChIP)-sequencing analysis, Koizumi et al. have demonstrated that JunB can facilitate DNA-binding of IRF4 at sites located 
near Icos (18). In addition, NF- $\kappa \mathrm{B}$ also plays an essential role in Treg identity and function, among which two canonical subunits are c-Rel and RelA (p65). NF- $\kappa \mathrm{B}$ c-Rel is critical for thymic Treg development, and it was also shown to be important for the function of activated Tregs, as a number of genes associated with homeostasis and function of aTregs were dramatically downregulated in c-Rel-deficient Tregs, whereas RelA (p65) mediates the development, survival, and function of eTregs (19-21). RelA-deficient Tregs were observed to show a significant reduction in the expression of eTreg signature genes, such as Icos, Tigit, and Il10, which share some similarities with IRF-4-deficient Tregs (21). However, RelA acts independently of IRF4 in the regulation of eTreg development and function. TNFRSF signaling, particularly GITR or TNF signaling, was demonstrated to activate RelA independent of TCR signals, thereby regulating Treg cell function (21).

In addition, it is intriguing that, regardless of IL-10, a small but significant subgroup of $\mathrm{ICOS}^{+}$Tregs were shown to produce IFN- $\gamma$ and IL-17 as well as the corresponding specific transcription factors T-bet and ROR $\gamma t$ in normal human peripheral blood and in draining lymph nodes of DNFBsensitized mice $(10,13)$. Thus, although most studies have defined $\mathrm{ICOS}^{+}$Tregs as a subset of activated Tregs with high suppressive function, we still have some reservations regarding these IL-17 or IFN- $\gamma$ producing Treg cells. One reason is that the identification of Tregs based on CD25 and FOXP3 expression cannot guarantee that all the identified cells are real Tregs. It is inevitable that a small group of activated effector $\mathrm{T}$ cells are included in $\mathrm{CD}_{2} 5^{+} \mathrm{FOXP}^{+} \mathrm{T}$ cells, $(22,23)$ which could be IL-17 or IFN- $\gamma$ positive, and this proportion could be even higher in inflammatory environment. Another reason is that the stability and function of IL-17 or IFN- $\gamma$ producing Tregs remain unelucidated.

Recently, a series of studies have been done to investigate the specific identities of T-bet ${ }^{+} / \mathrm{ROR} \gamma \mathrm{t}^{+}$Tregs or IFN- $\gamma^{+} / \mathrm{IL}-$ $17^{+}$Tregs in homeostasis and various disease conditions. T-bet ${ }^{+}$ Tregs have been demonstrated to be detectable in the steady state and show an increased frequency and absolute number during type 1 immune responses, thereby playing an important role in the maintenance of Treg homeostasis in the inflammatory environment $(24,25)$. Although T-bet ${ }^{+}$Tregs could not represent a stable Treg subset in the steady state, as the expression of T-bet in Tregs can be easily influenced by cytokine environment in vitro and in vivo, thus displaying a highly dynamic pattern, (25) $\mathrm{T}$-bet $^{+}$ Tregs were shown to be necessary and capable of restraining the proinflammatory role of pathological T cells (26). Remarkably, only a small proportion of $\mathrm{FOXP}^{+}{ }^{+} \mathrm{T}_{\text {-bet }}{ }^{+}$cells are IFN- $\gamma$ positive in the steady state (24). Similarly, ROR $\gamma \mathrm{t}^{+}$Tregs can also be detected in lymphoid and non-lymphoid tissues of mice in the steady state (27). In particular, significantly higher ROR $\gamma \mathrm{t}$ expression was observed in colonic Tregs, which is probably induced by symbiotic microbiota (27-29). These colonic ROR $\gamma \mathrm{t}^{+}$ Tregs display a CD44 ${ }^{\text {hi }}$ CD62 $\mathrm{L}^{\text {lo }}$ eTreg phenotype with absent expression of Helios or Nrp-1 and a low degree of demethylation in $I k z f 2$ (Helios) site, indicating that they are derived from pTregs (27-29). Additionally, these colonic ROR $\gamma \mathrm{t}^{+}$Tregs were shown to be relative stable, although they were observed to loss
FOXP3 expression slightly higher than FOXP3 ${ }^{+}$Tregs when transferred to lymphopenic mice together with naïve $\mathrm{T}$ cells, and to be necessary to maintain colonic homeostasis, displaying a superior regulatory capacity to prevent colitis (27). Moreover, these colonic ROR $\gamma \mathrm{t}^{+}$Tregs express IL-10 but few $\mathrm{IL}-17^{+}$cells even in inflamed colon $(27,28)$.

However, consistent with the idea that strong self-antigen stimulation could promote the loss of FOXP3 expression in Tregs, thus favoring ex-Treg formation in inflammatory setting, (30) a large number of transferred CBir1-specific FOXP3 ${ }^{+}$Tregs in TCR $\beta \mathrm{x} \delta^{-/-}$mice that were induced in vitro by culturing naïve $\mathrm{CD}^{+}{ }^{+} \mathrm{T}$ cells in the presence of TGF- $\beta$ lost FOXP3 expression and converted to IFN- $\gamma^{+} / \mathrm{IL}-17^{+} \mathrm{T}$ cells, and a fraction of transferred cells obtained IL-17 ${ }^{+} / \mathrm{IFN}-\gamma^{+}$Treg phenotype (31). This phenomenon could also be partly explained by their use of in vitro induced Tregs (iTregs) in the experiments, as iTregs are less stable than tTregs to maintain FOXP3 expression due to conserved non-coding DNA sequence (CNS) $2 \mathrm{CpG}$ island hypermethylation (32). Additionally, although these CBir1specific Foxp $3^{+}$IFN- $\gamma^{+}$T cells retained suppressive ability, it was observed that these FOXP $3^{+}$IFN $-\gamma^{+}$T cells can differentiate into IFN- $\gamma^{+}$T cells ultimately (31). Similarly, $\mathrm{CD} 4^{+} \mathrm{FOXP}^{+} \mathrm{IL}^{-17 \mathrm{~A}^{+}}$ $\mathrm{T}$ cells in the dermis of lesional skin and an enhanced propensity of purified peripheral blood Tregs to convert to IL-17A ${ }^{+}$T cells after ex vivo stimulation compared with healthy individuals have been shown in severe psoriatic patients (33). Therefore, it is hard to say whether the stability and the inhibitory capacity of $\mathrm{ICOS}^{+} \mathrm{IFN}-\gamma^{+} / \mathrm{IL}-17^{+}$Tregs that are observed in both the steady state and inflammatory condition are still retained. Activated eTregs have been shown to be less stable than cTregs to maintain FOXP3 expression and ICOS-induced higher PI3K signaling also contributes to this instability $(34,35)$. The stability and function of these specific ICOS ${ }^{+}$Tregs need further detailed inspection.

\section{The Role of ICOS Signaling in Tregs}

According to various studies, ICOS is generally involved in the production, proliferation and survival of Tregs, providing them a strong suppressive capability, which we will discuss separately below.

First, ICOS can mediate the generation of FOXP3 ${ }^{+}$Tregs. Compared with healthy individuals, $\mathrm{CD} 4{ }^{+} \mathrm{CD} 25^{-} \mathrm{T}$ cells from a small subset of common variable immunodeficiency (CVID) patients who have a homozygous genomic deletion of ICOS cannot induce anergic T cells with immature myeloid DCs, (36) which are involved in maintaining peripheral tolerance by the induction of Tregs (37). Furthermore, the ablation of ICOS in unmanipulated mice was shown to result in a reduced number of FOXP3 ${ }^{+}$Tregs compared to that observed in WT mice (38, 39). Blockage of ICOS-ICOSL ligation when culturing human naïve $\mathrm{CD}^{+} \mathrm{T}$ cells with $\mathrm{CD} 40$-activated $\mathrm{B}$ cells in vitro was also shown to decrease FOXP3 levels, thereby impairing the generation of FOXP3 ${ }^{+}$Tregs (40). These phenomena confirm the importance of ICOS for the transcriptional activity of Foxp3, which could be illustrated by favoring the combination of nuclear factor of activated $\mathrm{T}$ cells (NFAT) to FOXP3 over NFAT to activator protein 1 (AP-1) (41). In addition, ICOS-deficient Treg 
cells showing Foxp3 instability due to significant methylation of Foxp3 CNS2 may be another reason for the reduction of Tregs (14). However, the reduced frequency of FOXP3 ${ }^{+}$Tregs in the periphery should not be attributed to the dysfunction of the thymus, as $I \cos ^{-1-}$ mice exhibit a similar percentage of FOXP3 ${ }^{+}$ $\mathrm{T}$ cells in the thymus compared with WT mice (38). In contrast, by analyzing TCR excision circles, a significant increase in the thymic output of Tregs was detected in $\mathrm{Icos}^{-/-}$mice compared with that observed in WT mice (14).

Second, the ICOS signal aids in promoting the proliferation of Tregs. The superior proliferative capacity of $\mathrm{ICOS}^{+}$Tregs has been confirmed by a higher Ki-67 expression expressed on these cells $(42,43)$. ICOSL expressed on plasmacytoid DCs was demonstrated to preferentially promote ICOS $^{+}$Treg proliferation by engaging with ICOS on Tregs in vitro (9). When immunizing Icosl $^{-/-}$mice with endotoxin-free ovalbumin (OVA), which is known to facilitate Treg proliferation, the proportion of $\mathrm{FOXP}^{+}$antigen-specific Tregs was significantly lower than that observed in WT mice, suggesting a great effect for ICOS co-stimulation in the expansion of Tregs (38). Likewise, a delayed and insufficient Treg expansion was also observed in C57BL/6 Icos ${ }^{-/-}$mice during helminth infection (44). Nevertheless, the results of assays using BrdU to track T cell proliferation indicated that no difference in BrdU uptake was observed in FOXP3 ${ }^{+}$Tregs from $\mathrm{Icos}^{-/-}$mice upon infection compared with that observed in WT mice. The deficiency of Tregs could result from the enhanced apoptosis of $I \cos ^{-/-}$Tregs (44). From this perspective, the auxo-action of ICOS to Treg proliferation and survival is hard to clearly measure.

Indeed, ICOS signaling is highly involved in the survival of Tregs. When murine CFSE-labeled Tregs were stimulated with anti-CD3 antibody for 2 days, ICOS $^{-}$Tregs died within the few hours after TCR stimulation, while ICOS $^{+}$Tregs became hyperproliferative, suggesting a death tendency of Tregs with absent ICOS expression (43). Furthermore, during the in vitro stimulation culture in the presence of IL-2, purified mouse $\mathrm{ICOS}^{+}$Tregs from lymph node and spleen expressed a higher level of Bcl-2, an anti-apoptotic molecule belonging to the Bcl-2 super family, than $\mathrm{ICOS}^{-}$Tregs (42). But the higher expression of Bcl-2 in $\mathrm{ICOS}^{+}$Tregs could also be partly explained by the addition of IL-2, as Bcl-2 is known to be sensitive to IL2 stimulation, and $\mathrm{ICOS}^{-}$Tregs do not respond to IL-2 like ICOS $^{+}$Tregs and therefore do not upregulate $\mathrm{Bcl}-2$ expression (42). Indeed, CD $44{ }^{\text {hi }}$ CD62L ${ }^{\text {lo }}$ eTregs that express high levels of ICOS exhibit low Bcl-2 expression under steady state conditions, and these Bcl-2 $2^{\text {lo }}$ eTregs were observed to be selectively lost after 2 weeks of ICOSL blockage in WT mice, indicating an important anti-apoptotic role of ICOS signaling in promoting Bcl-2 $2^{\text {lo }}$ eTregs survival (12).

However, Bcl-2 is not exclusively important for Treg survival. There are many other molecules belonging to the Bcl-2 family involved in the regulation of Treg survival, especially Bim and Mcl-1. Chougnet et al. reported that Tregs accumulation in aged mice could be attributed to the increased survival due to decreased expression of Bim in Tregs, while neither Bcl-2 nor Mcl-1 contributes to the increased survival in old Tregs (45). It was demonstrated further that the reduced Bim expression in
Tregs mainly promotes effector, but not central, Tregs accrual, as the accumulated Tregs in aged mice are mainly CD $44{ }^{\text {hi }} \mathrm{CD} 62 \mathrm{~L}^{\text {lo }}$ eTregs, and Treg-specific or germline deletion of Bim cannot rescue the decreased number of cTregs with age in mice (46). Moreover, Mcl-1, but not other anti-apoptotic proteins including $\mathrm{Bcl}-\mathrm{xl}$ and $\mathrm{Bcl}-2$, has been demonstrated to be particularly important for the survival of Tregs to maintain homeostasis (47).

These two essential proteins have also been shown to be included in ICOS-mediated survival signals. By comparing the expression levels of ICOS on Tregs in mice of different ages, Raynor et al. showed a coordinating increase in ICOS expression with the age-dependent accrual of regulatory $\mathrm{T}$ cells in old mice and indicated an effect of ICOS/ICOSL interaction on Tregs homeostasis, which is mediated by antagonizing Bim in eTregs (46). The increased levels of IL-6 that occurs with age enhanced TCR-driven ICOS expression, thereby attenuating Bim expression and sustaining aged effector Tregs survival, possibly though PI3K/Akt/FOXO pathway (46). Moreover, ICOS-ICOSL interaction could yield the recruitment of PI3K components, leading to cross activation of the PI3K-Akt downstream signals, which was previously suggested to mediate anti-apoptotic effects. For instance, blocking p110 $\delta$ with the selective inhibitor CAL101 can lead to sufficient GSK-3 $\beta$ activation, resulting in the degradation of the anti-apoptotic protein Mcl-1 and effectively impeding Tregs survival (48). In summary, ICOS signaling can mediate Treg survival by fine-tuning the expression of multiple anti-apoptotic and pro-apoptotic molecules of Bcl-2 family.

In addition, one cytokine that is worth mentioning is IL-2, which is also regarded as being essential for the expansion and survival of Tregs. IL-2 signaling was shown to induce FOXP3 expression during the Treg development in the thymus and was observed to be widely involved in Treg differentiation, lineage stability, proliferation, and function (49). Phosphorylation of STAT5 could be an important hallmark for the activation of the IL-2 signals. It was demonstrated that PSTAT5 $^{+}$Tregs exist as discrete clusters in secondary lymphoid tissues of mice with IL2-producing proto-effector T cells and DCs to exert suppressive functions, making effects to maintain immune homeostasis (50). Moreover, some survival factors that can be regulated by ICOS have also been observed to be regulated by IL-2. For example, IL-2 addition can increase Mcl-1 expression in vitro and in vivo (47). Here, we would like to discuss the effect of IL-2 to ICOS ${ }^{+}$ Tregs and the non-redundant role of IL-2 and ICOS signaling in Treg biology.

As is reported by Kornete et al., the effect of IL-2 to ICOS + Tregs is much more than the superficial cognition that it promotes Tregs expansion, IL-2 gives a functional fitness to $\mathrm{ICOS}^{+}$Tregs (42). In other words, $\mathrm{ICOS}^{+}$Tregs are more sensitive to IL-2 stimulation and more dependent on IL-2 to maintain their survival than ICOS $^{-}$Tregs. They observed a higher responsiveness to IL- 2 in ICOS ${ }^{+}$Tregs, as a fold increase of surface marker CD25, a high-affinity IL-2 receptor component, and STAT5 phosphorylation were detected in $\mathrm{ICOS}^{+}$Tregs when culturing Tregs from BCD2.5 Foxp3 ${ }^{\mathrm{GFP}}$ mice with APCs (42). Furthermore, the withdrawal of IL-2 led to an apoptotic tendency of $\mathrm{ICOS}^{+}$Tregs during the culturing of separated $\mathrm{ICOS}^{+}$Tregs and ICOS $^{-}$Tregs, which could be rescued by re-adding IL-2 (42). 
This result was not only observed in mice, but has also been reproduced in human cells, indicating an important role of IL-2 in the survival of $\mathrm{ICOS}^{+}$Tregs in vitro (9).

However, it should be noted that ICOS may promote Treg proliferation or survival independently of IL-2 signaling in vivo. On one hand, the ablation of ICOS was observed to reduce the inhibitory function of Tregs without affecting their reactivity to IL-2, as I $\cos ^{-/-}$BDC2.5 Tregs exhibited no difference with WT Tregs in their intrinsic responses to IL-2, (42) and transferring OT-II T cells into $\mathrm{Icos}^{-/-}$mice did not affect IL-2 production by these $\mathrm{T}$ cells (38). On the other hand, the results of a study using C57BL/6 mouse model have indicated that blockage of IL2 signaling results in significant loss of $\mathrm{CD} 44^{\mathrm{lo}} \mathrm{CD} 62 \mathrm{~L}^{\mathrm{hi}} \mathrm{CCR} 7^{\mathrm{hi}}$ cTregs without significantly impacting the number or the proportion of $\mathrm{CD} 44^{\text {hi }} \mathrm{CD} 62 \mathrm{~L}^{\text {lo }} \mathrm{CCR} 77^{\text {lo }}$ eTregs, which express high levels of ICOS, in the lymphoid or non-lymphoid tissues (12). Moreover, although a great increase of CD25 expression was observed in $\mathrm{ICOS}^{+}$Treg after IL-2 stimulation in vitro, eTregs express a lower level of CD25 and less depend on IL2 than cTregs for their maintenance in vivo (12). The signaling switch from IL-2 to ICOS in eTregs is probably due to the unique environment where eTregs are located, as they mostly populate in peripheral tissues, in which IL-2 is not prevalent, whereas cTregs are continuously circulating between lymphoid tissues and blood and could easily gain access to IL-2 in the T cell zones of secondary lymphoid organs (12). In addition, Zhang et al. further demonstrated that this signaling switch in eTregs can cause FOXP3 instability, consistent with the opinion that a small fraction of activated Tregs could loss FOXP3 expression and transform into Th cells under disease conditions (34).

Last but not least, ICOS endows Tregs with a stronger suppressive function. Recent many studies have shown the significance of the ICOS-ICOSL signaling pathway for the selftolerance mediated by Tregs. Icos ${ }^{-1-}$ mice, which fail to develop respiratory tolerance induced by intranasal $\mathrm{Ag}$ application, display no significantly increase in splenic and lung-resident $\mathrm{CD} 4^{+} \mathrm{FOXP}^{+}$Tregs after being immunized with OVA and a decreased ability to secrete IL-10 compared with that observed in WT mice (39). Similarly, $\mathrm{ICOS}^{+}$Tregs were suggested as a dominant Treg subset to prevent NOD mice from the development of diabetes, and a drastic reduction in ICOS expression on pancreatic Tregs was observed as NOD mice progressed from prediabetic stage to overt diabetes (42).

The stronger inhibitory ability of $\mathrm{ICOS}^{+}$Tregs than $\mathrm{ICOS}^{-}$ Tregs was partly relies on the higher expression levels of IL10. Indeed, as early as in 2003, Löhning et al. observed that ICOShigh $\mathrm{T}$ cells were closely correlated with the expression of IL-10 (8). Soon afterward, ICOS-dependent IL-10 production was demonstrated to be indispensable for the acquisition of the suppressive ability of $\mathrm{T}$ cells generated in $\mathrm{DO} \times \mathrm{OVA}^{\text {high }}$ mice, which presented a self-tolerance phenotype with low numbers of $\mathrm{T}$ cells and a reduced proliferative ability compared to $\mathrm{DO} \times \mathrm{OVA}^{\text {low }}$ mice, owning to the largely generated IL-10producing $\mathrm{CD}^{+} \mathrm{T}$ cells (51). Furthermore, $\mathrm{ICOS}^{+}$Tregs and ICOS $^{-}$Tregs were shown to exert inhibitory function through different molecular mechanisms. ICOS ${ }^{+}$Tregs produce higher amount of IL-10 but lower level of TGF- $\beta$ than ICOS $^{-}$Tregs.
By adding a neutralizing antibody against IL-10 or blocking TGF- $\beta$ signaling with a pharmacological inhibitor when culturing $\mathrm{ICOS}^{+}$or $\mathrm{ICOS}^{-}$Tregs with naïve T cells in vitro, the inhibitory function $\mathrm{ICOS}^{+}$Tregs was shown to be mediated through both IL-10 and membrane TGF- $\beta$ (mTGF- $\beta$ ), whereas ICOS ${ }^{-}$Tregs only used mTGF- $\beta$ in the cell-cell contact dependent manner (9).

However, although some studies suggested a correlation between ICOS expression and IL-10 secretion, other researchers observed no reduction of IL-10 production when ICOS ligation was blocked. For example, ICOS deficiency resulted in a large reduction in FOXP3 ${ }^{+}$Tregs in the spleen and colonic lamina propria but a similar level of IL-10 expression relative to that observed in $I \cos ^{+/+}$mice (14). In addition, IL-10 was shown to be unnecessary for ICOS-mediated suppressive function in some cases. The intranasal application of Protollin inhibited allergen-induced airway hyperresponsiveness (AHR) through toll-like receptor (TLR) 4 dependent ICOS $^{+}$Tregs induction (52). However, IL-10 was demonstrated to be dispensable for its inhibition of experimental asthma, although increased Il10 mRNA could be detected in nasal associated lymphoid tissue (NALT) harvested from mice 14 days after Protollin administration (52). These conditions not only indicate the possibility that there are other IL-10-producing $\mathrm{CD}^{+}{ }^{+} \mathrm{FOXP} 3^{-}$ $\mathrm{T}$ cells that can compensate the reduced secretion of IL-10 induced by ICOS signaling in its absence, more importantly, there are also other ways for ICOS to mediate the inhibitory function of Tregs. In other words, the part of ICOS signaling that mediates the suppressive function of Tregs incompletely overlaps with the IL-10 signals. As an example, blockage of IL10R or ICOSL was observed to cause divergent outcomes to mice with chronic toxoplasma gondii infection (53). Treatment with anti-IL-10R blocking $\mathrm{Ab}$ increased $\mathrm{CD}^{+}{ }^{+} \mathrm{FOXP}^{-}{ }^{-}$effector $\mathrm{T}$ cell expansion, activated APCs, recruited numerous neutrophils to the brain and led to an eventually fatal immunopathology, whereas blocking ICOS signaling only resulted in a non-lethal expansion of T cells without limited IL-10 expression or APC activation (53). Additionally, IL-10-deficient mice develop more severe disease than $\operatorname{Icos}^{-1-}$ mice $(38,54)$. Although $\mathrm{B}$ and $\mathrm{T}$ lymphocytes are generated normally in both knockout mice, germline deficiency for Il10 leads to development of chronic enterocolitis spontaneously, whereas Icos ablation does not (38, 54). Using Treg-specific IL-10 knockout mice, it was further shown that Treg-derived IL-10 production can help to keep immune responses in check at mucosal interfaces (55).

At present, the mechanism underlying the ICOS-associated suppressive function of Tregs is still unclear. For one thing, it remains confusing how the downstream pathways of ICOS ligation induce Il10 transcription. Recently, the results of many studies have confirmed the correlation between the increased expression of ICOS and the overexpression of CTLA-4, GITR, lag3, TIGIT, and CD69 on Tregs, $(9,15,56,57)$ and some of these upregulated markers have been shown to be involved in exerting the suppressive function of Tregs through IL-10 induction (Figure 1) $(58,59)$. For example, $\mathrm{CD}^{+} 9^{+}$Tregs, which highly express ICOS, were shown to be unable to exert their inhibitory function in Il10 knockout mice (57). Similarly, compared with TIGIT $^{-}$Tregs, TIGIT $^{+}$Tregs expressed higher 


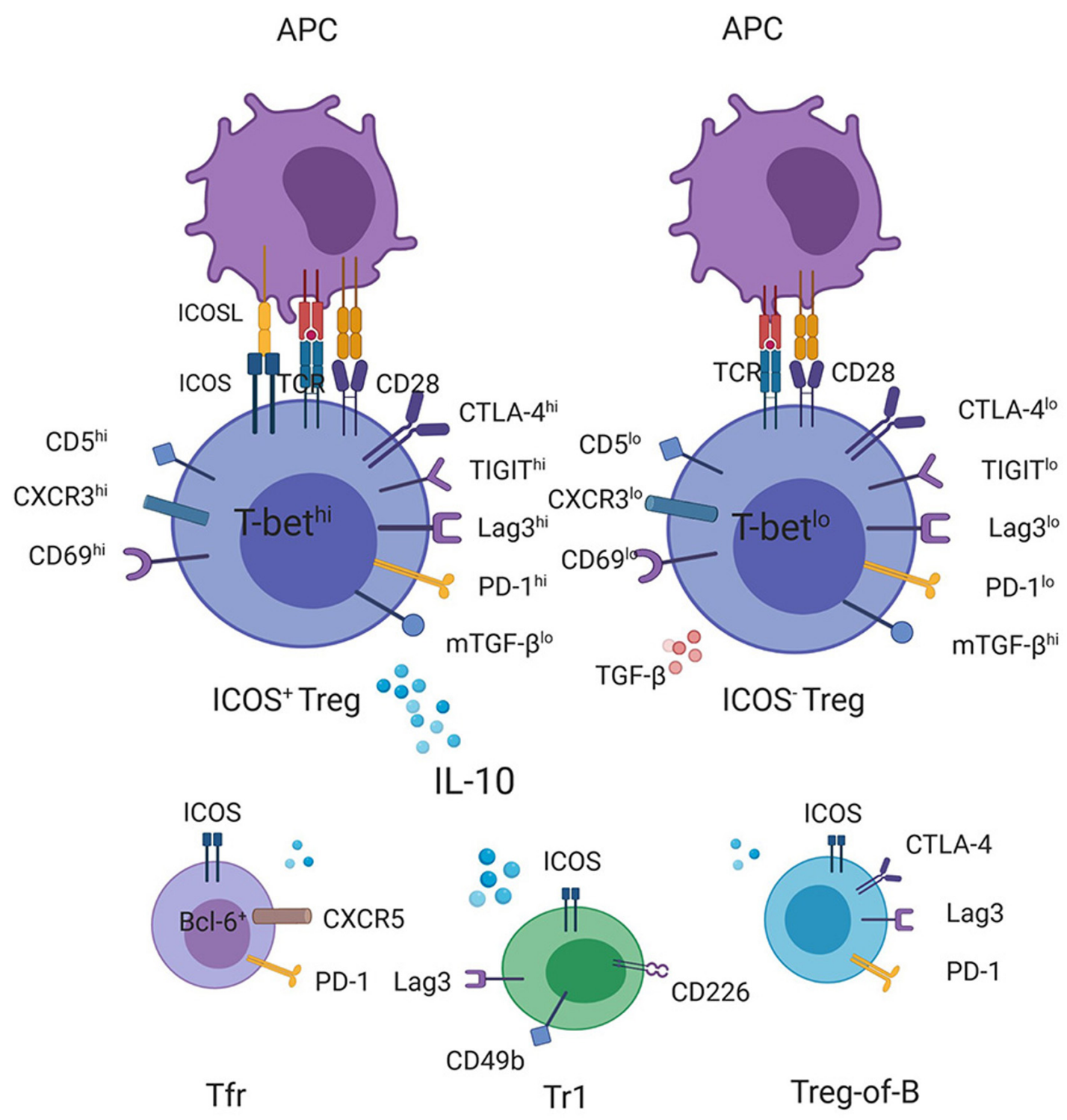

FIGURE 1 | Production of IL-10 by ICOS-expressing T cells with regulatory function. CD4+ ICOS ${ }^{+}$Tregs express high levels of IL-10 but smaller amounts of TGF- $\beta$ compared with ICOS- Tregs. Transcriptome and FACS analyses have demonstrated a correlation between the increased ICOS expression on Tregs with the high expression levels of CD5, CD69, CXCR3, and T-bet as well as some checkpoint inhibitors, such as CTLA-4, TIGIT, Lag3, and PD-1, (15, 56, 57) some of which have been shown to promote the transcription of the IL-10 gene, contributing to high levels of IL-10 secretion together with ICOS. In addition, other ICOS-expressing regulatory cells, such as Tr1, Treg-of-B cells, and Tfr cells, can also be the source of IL-10.

amounts of ICOS and other co-inhibitory molecules, including CTLA-4, PD-1, Lag3, and Tim3, and exhibited high levels of IL-10 expression, endowing Tregs inhibitory capabilities (15). However, despite TIGIT ligation induced Il10 gene expression in vitro, IL-10 was not detectable in culture supernatants of TIGIT agonist-treated Tregs, which was isolated from immunized mice and was restimulated for 2 days in vitro (15). Additionally, deletion of Fgl2, an important mediator for TIGITmediated Treg suppressive function, did not affect TIGHTmediated IL-10 induction in $\mathrm{Fgl}^{-/-}$Tregs in vitro, indicating that the TIGIT-related IL-10 pathway diverges from TIGITCEBP $\alpha$-Fgl2 inhibitory signaling pathway (15). Therefore, the upstream signaling pathways of IL-10 as well as the interaction between ICOS and these molecules that promote IL-10 secretion require further study. For another thing, the existence and transmission mode of the ICOS-related but IL-10 independent suppressive signals remain an enigma. In addition to the direct inhibition mechanism mediated by ICOS, an enhanced migration of Tregs to target organs mediated by ICOS could also contribute to their increased inhibitory function. Co-stimulation with ICOS was shown to downregulate CD62L and CCR7 while upregulating many chemokine ligands on $\mathrm{CD} 4^{+} \mathrm{T}$ cells, which led to reduced homing capacity to lymph nodes but increased accumulation of Treg cells in target tissues $(60,61)$. For example, using 
photoconvertible fluorescent proteins to track Tregs recirculating between inflamed colon and the distal part of mesenteric lymph nodes, these migratory Tregs were discovered to display a highly immunosuppressive phenotype with a high expression of ICOS, Lag3, CTLA-4, CD103, PD-1, and CCR5 while exhibiting reduced expression of CCR7 (62). Intestinal inflammation increased Treg turnover as well as the number of Tregs with an inhibitory phenotype mentioned above, which contributed to controlling dextran sodium sulfate (DSS)-induced colitis (62). Additionally, except for ICOS $^{+}$Tregs, Tr1 cells, Tfr cells, and B-cell induced $\mathrm{CD}^{+}{ }^{+}$Foxp $^{-}$regulatory $\mathrm{T}$ cells (Treg-of-B cells), which also highly express ICOS, can exert suppressive abilities in vitro and in vivo $(6,63)$.

\section{PI3K Signaling and ICOS in Tregs}

The most thoroughly studied downstream signaling pathway in $\mathrm{ICOS}^{+}$Tregs is the PI3K signal pathway. The class $\mathrm{I}_{\mathrm{A}}$ phosphatidylinositol 3-kinase (PI3K), which is widely involved in relaying signals from TCR and co-stimulatory receptors of $\mathrm{T}$ cells, are heterodimeric enzymes made up of a regulatory subunit (p85 $\alpha, \mathrm{p} 55 \alpha, \mathrm{p} 50 \alpha, \mathrm{p} 85 \beta$ or p $55 \gamma$ ) and a catalytic subunit (p110 $\alpha, \mathrm{p} 110 \beta$, or $\mathrm{p} 110 \delta$ ) (64). Although there is no difference in the expression levels of $\mathrm{p} 110 \alpha, \mathrm{p} 110 \beta$, or $\mathrm{p} 110 \delta$ in Tregs and Tcons, p110 $\delta$ plays an indispensable role in Treg cells (48). ICOS cross-linking results in the phosphorylation of $\mathrm{Tyr}^{181}$ in the YMFM motif, which binds to the $\mathrm{SH} 2$ domain of $\mathrm{p} 85 \alpha$ or $\mathrm{p} 50 \alpha$, and further recruits the p110 catalytic subunit to activate downstream molecules, such as the lipids phosphatidylinositol $(3,4)$-biphosphate (PIP2) that is subsequently converted to phosphatidylinositol 3,4,5-trisphosphate (PIP3) at the inner leaflet of the cytomembrane under the catalysis of p110 (64). After that, PIP3 phosphorylates Akt, which activates complex downstream signals, thus playing an essential role in Treg cell proliferation, survival as well as metabolism, some details of which are discussed in the preceding section (Figure 2).

In addition, the PI3K-mTORC signal is also involved in the regulation of ICOS in Tregs. As an intracellular energy metabolism receptor, the mammalian target of rapamycin (mTOR), which is comprised of mTOR complex 1 (mTORC1) and mTORC2, integrates immune and metabolic signals inside and outside $\mathrm{T}$ cells, participates in the maintenance of $\mathrm{T}$ cell homeostasis, and determines the fate of cells (65). Under steady state conditions, Tregs display elevated phosphorylation of two major substrate molecules downstream of mTORC1, 4E-BP1 and S6, compared with naïve T cells (66). Although numerous studies have revealed a negative effect of the mTORC signaling on the de novo differentiation and population expansion of Tregs, $(67,68)$ and mTORC1 and mTORC2 are likely to mediate the inhibition of Treg differentiation through different mechanisms, (65) mTORC1 is suggested to be responsible for the homeostasis and suppressive activity of Tregs (66). Zeng et al. demonstrated that selective deletion of Raptor in Tregs caused profound inflammatory diseases accompanied by lymphoproliferative manifestation in Foxp $3^{\text {cre }}$ Raptor ${ }^{\mathrm{fl} / \mathrm{fl}}$ mice,

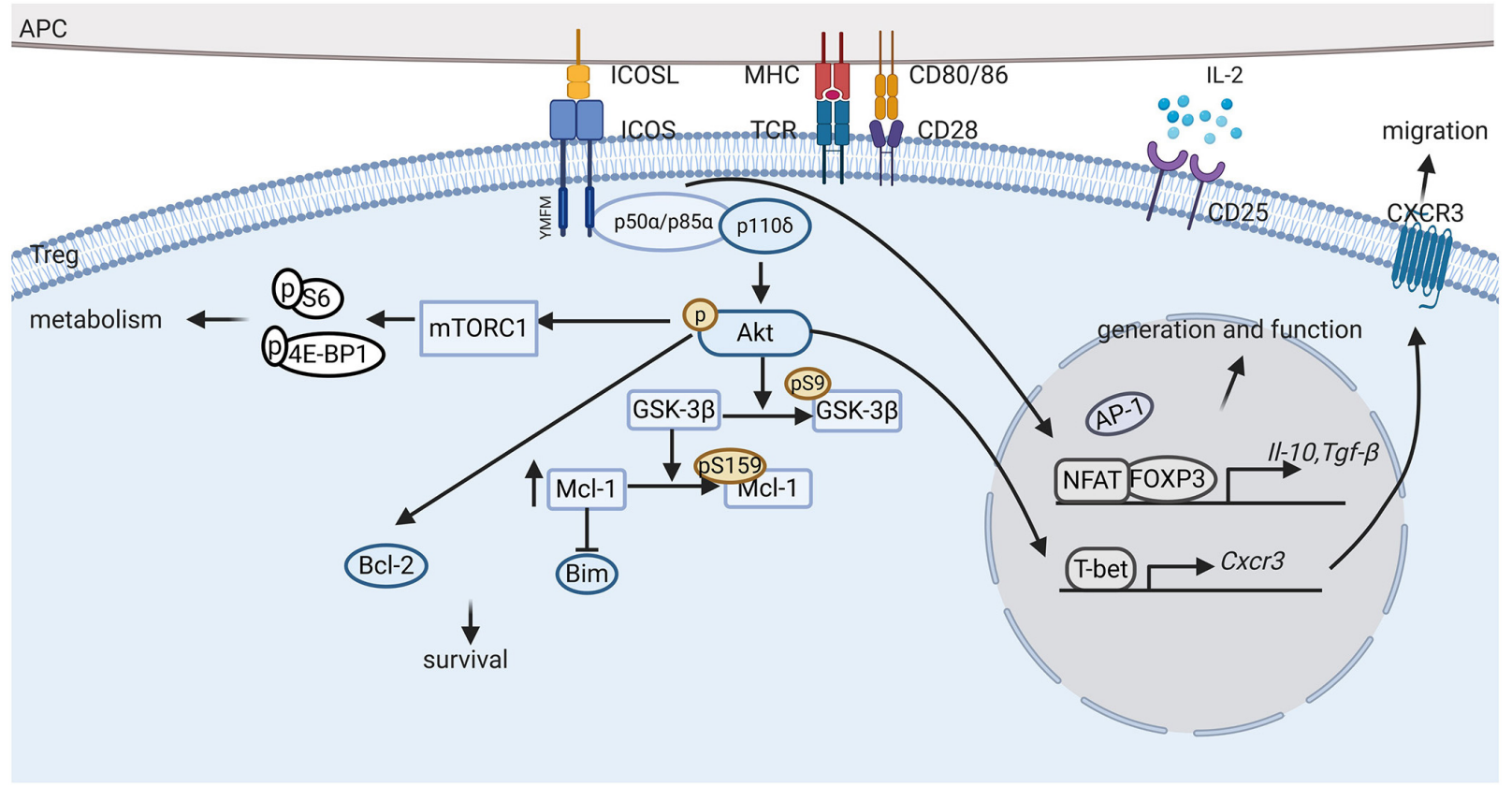

FIGURE 2 | ICOS signaling pathway in Tregs. ICOS-ICOSL interaction promotes the generation, proliferation, survival and suppressive ability of regulatory T cells (Tregs) through complex signaling pathways. First, activation of ICOS promotes Foxp3 transcription, favoring NFAT binding to FOXP3 over AP-1 and upregulating FOXP3 downstream regulatory genes, such as $1 /-10$ and Tgf- $\beta$. Second, ICOS engagement induces PI3K recruitment to the YMFM motif at the cytoplasmic tail and the phosphorylation of Akt. Activation of Akt can induce Bcl-2 expression and inhibit pro-apoptotic Bcl-2 family protein production, thereby promoting ICOS ${ }^{+}$Treg survival. Furthermore, ICOS also activates the mTORC1 signals, which is suggested to mediate protein synthesis and metabolism in Tregs. In addition, ICOS expression elevates CXCR3 expression, which promotes the migration of Tregs to inflammatory tissues. 
despite these Raptor-deficient Tregs exhibited normal FOXP3 expression and retained the capacity to produce the antiinflammatory cytokines, TGF- $\beta 1$ and IL-10 (66). Whereas, Raptor-deficient Tregs showed decreased expression of CTLA4 and ICOS, two important molecules for Treg function, and impaired proliferation ability in a disease-free environment. Furthermore, they suggested that Raptor/mTORC1 signaling can regulate cholesterol/lipid metabolism through the mevalonate pathway, promoting enhanced Treg proliferation and CTLA-4 and ICOS upregulation, which increase Treg function (66). In addition, despite the mTORC1 signaling have been demonstrated to be essential to the homeostatic proliferation of Tregs, $\mathrm{Xu}$ et al. reported that a half reduction of mTORC1 signaling in Tregs did not apparently influence the expansion and suppressive function of FOXP3 ${ }^{+}$Tregs in Raptor ${ }^{\mathrm{fl} /}+{ }_{\text {Foxp }} 3^{\mathrm{Cre}}$ mice after OVA/CFA immunization (69). In contrast, a decrease in the percentage and absolute number of $\mathrm{FOXP} 3^{+} \mathrm{CXCR}^{+}$Tfr cells was observed in Raptor ${ }^{\mathrm{fl} /}{ }^{+}$Foxp $3^{\mathrm{Cre}}$ mice compared with that observed in WT mice, and these Raptor ${ }^{\mathrm{fl} /}+\mathrm{Tfr}$ cells also expressed a decreased level of CTLA-4, ICOS, and PD-1 (69). Indeed, the mTORC1 signaling is critical for both the de novo differentiation of Tfr cells from conventional Tregs precursors by activating mTORC1-p-STAT3-TCF-1-Bcl-6 axis and their suppressive functions (69). Moreover, except for the fact that mTORC1 signaling could promote ICOS expression in Tfr cells, ICOS signaling also promotes Tfr cell differentiation and function in immunized mice (70).

The PI3K-mTORC2 signaling also plays an essential role for Tregs differently from mTORC1 signaling. PETN-mTORC2 can regulate metabolic balance between glycolysis and mitochondrial fitness in Tregs which is probably associated with Treg stability (71). Compared with effector T cells, Tregs maintain high levels of PTEN to control PI3K signal strength at an appropriate level, which is essential for Tregs to maintain lineage stability and homeostasis (35). This condition can also be supported by the fact that activated eTregs, which upregulate ICOS expression and activate PI3K signaling, can be less stable than cTregs (34). Deletion of PTEN disables Treg to maintain an activated phenotype and fails to create a suppressive tumor microenvironment, therefore displaying a protective role in tumor models (72). Pten- $\Delta$ Treg mice, which specifically delete PTEN in FOXP3 ${ }^{+}$Tregs, develop an autoimmunelymphoproliferative disease featured by uncontrolled Th1 and Tfh responses and excess germinal center formation $(35,71)$. PTEN deletion causes great Treg proliferation and higher expressions of CD44, CD69, ICOS, and PD-1 but a lower expression of CD62L in Pten ${ }^{\mathrm{fl} / \mathrm{fl}} \mathrm{Foxp}{ }^{\mathrm{Cre}}$ Tregs, indicating an activated phenotype $(35,71)$. However, these PTEN-deficient Tregs are unstable, which could spontaneously downregulate CD25 and subsequently loss FOXP3 expression during in vitro culture with IL-2 supplementation and as Pten- $\Delta$ Treg mice age, and might be pathogenic as they could not resolve the induced experimental autoimmune encephalomyelitis in Pten-ATreg mice (35). The loss of function of PTENdeficient Tregs could be restored by inhibition of mTORC2 signaling that is upregulated after PTEN deficiency (71). In addition, PTEN-mTORC2 axis has also been shown to be important for $\mathrm{Tfr}$ cells to suppress Tfh and germinal center responses (71).

\section{SIMILARITIES AND DIFFERENCES BETWEEN ICOS AND OTHER CD28 FAMILY MEMBERS}

\section{ICOS and CD28}

As a member of the CD28 family, human ICOS is a type-I transmembrane protein that shares $24 \%$ identity with CD28 and $17 \%$ identity with CTLA-4 (1). Previous studies have reported a synergistic co-stimulatory effect of ICOS and CD28 to promote T cell activation, proliferation and function. However, there are still some differences in the downstream signals between ICOS and CD28, and they function in somewhat different ways.

ICOS possesses the YMFM motif at the cytoplasmic tail, which is the YMNM motif at the corresponding site of CD28 (73). The YMFM motif allows ICOS to preferentially recruit p50 $\alpha$ that has a stronger lipid kinase activity than $\mathrm{p} 85 \alpha$, therefore activating PI3K more strongly than CD28 (74). Transformation of asparagine (N) to phenylalanine $(\mathrm{F})$ in ICOS also causes it to lose the ability to bind with the $\mathrm{SH} 2$ domain of Grb2 that activates the NFAT/AP-1 site to promote IL-2 transcription (75). Furthermore, different abilities to activate MAPK have been observed, with CD28 exhibiting a stronger ability to phosphorylate p46 JNK (76). Moreover, the absence of an MYPPPY motif in the single immunoglobulin (lg)V-like extracellular domain inhibits the ability of ICOS to bind to B7-1/B7-2 like CD28 (77). Alternatively, ICOS interacts with a unique ligand ICOSL, which is also expressed on ILCs and some types of nonhematopoietic cells except for APCs, increasing its functionality. Additionally, upon TCR stimulation, ICOSL can be rapidly shed after binding to ICOS to maintain a proper strength of the costimulatory signal on $\mathrm{T}$ cells, but the same situation has not been observed in CD28-B7-1/B7-2 interaction $(78,79)$. This process is demonstrated to be mediated by the AMDM family-dependent proteolytic cleavage of ICOSL on B cells (80).

These differences between ICOS and CD28 signaling could lead to different effects on Tregs. It has been well established that CD28 plays an essential role in the development, proliferation, and function of Tregs. Cd28 $8^{-/-}$mice display a significant reduction of Tregs in the spleen and other secondary lymphoid organs compared with WT mice (81). Remarkably, CD28 is important for the development and homeostatic proliferation of tTregs, whereas the anti-apoptotic activity or slow proliferation in the steady state of pTregs was observed unaffected by CD28 deficiency (81). Wakamatsu et al. have also shown that pTregs were still abundant in the intestines of $C d 28^{-/-}$mice, although a weaker suppressive ability of these $C d 28^{-/-}$Tregs was observed, suggesting that pTregs can be developed in a CD28-independent manner (82). Additionally, during the in vitro generation of iTregs, CD28 stimulation was considered to be a limiting factor for the acquisition of Treg-specific DNA hypomethylation at the signature genes of Tregs (83). In contrast to CD28, ICOS deficiency seems not to impair thymus output of Tregs, although 
the number of Tregs was observed to be reduced by $30 \%$ in $\operatorname{Icos}^{-1-}$ mice $(14,38)$. Therefore, ICOS signaling may be more involved in Treg generation in the periphery and eTreg expansion and function. But it could not be excluded that the expression of tTreg signature genes is affected during the development in the thymus when ICOS signaling is absent, which should be clarified further. Furthermore, when isolated $\mathrm{ICOS}^{+}$Tregs were cultured in the presence of anti-CD3 mAb and IL-2, the addition of ICOSL was observed to facilitate Treg proliferation, whereas adding anti-CD28 mAb plus ICOSL strongly inhibited this promotion (9). This result not only indicates a negative effect of CD28 to promote ICOS $^{+}$Treg proliferation in vitro, but also emphasizes a proliferation promoting effect of ICOS independent of CD28. In addition, ICOS signaling induces the production of large amounts of IL-10 but limited IL-2 secretion, just opposite to CD28 signaling (76).

\section{ICOS and CTLA-4}

Unlike CD28 which is constitutively expressed on the surface of $\mathrm{T}$ cells, or ICOS which exhibits an inductive expression pattern, CTLA-4 is rarely detected on resting $\mathrm{T}$ cells but is predominately centralized in the intracellular compartments of Tregs and activated $\mathrm{T}$ cells (84). Only under specific conditions can CTLA- 4 be expressed on the cell surface. CTLA-4 interacts with B7-1/B7-2 with higher affinity and avidity than CD28 and plays the opposite role to CD28. Unlike $I \cos ^{-/-}$mice that remain healthy and have normal absolute number of lymphocytes in homeostasis, Ctla-4-/mice develop fatal lymphoproliferative disease, characterized by splenomegaly, lymphadenopathy, multiorgan lymphocytic infiltration, and tissue destruction $(38,85,86)$. Hyperproduction of $\operatorname{lgE}$ and $\lg \mathrm{G}$ reveals the susceptibility to autoimmune diseases of CTLA-4 deficient mice $(86,87)$. Similar but less severe symptoms are also observed in mice with Treg-specific CTLA4 deficiency, indicating that this disorder is largely attributed to loss of function of CTLA-4 deficient Tregs to suppress T cell responses (87). Additionally, Wing et al. have also demonstrated that CTLA-4 mainly affects Treg suppressive function in the periphery, the generation of FOXP3 ${ }^{+}$thymocytes is minimally altered in CTLA-4 conditional knockout mice (87).

Interestingly, CTLA-4 has been observed to be expressed at relatively higher levels on the surface of ICOS $^{+}$Tregs, (9) suggesting a subtle connection between these two molecules that belong to the same superfamily. However, considering that CTLA-4 deficiency, but not ICOS, is associated with the loss of immune tolerance, there raises a question of whether the superior suppressive ability of $\mathrm{ICOS}^{+}$Tregs relies on CTLA4 expression. Recently, Zheng et al. reported that blockage of the ICOS-ICOSL interaction decreased the surface expression of CTLA-4 in CD4 ${ }^{\text {hi }}$ Tregs induced by coculturing human naïve $\mathrm{CD}^{+}{ }^{+} \mathrm{CD} 45 \mathrm{RO}^{-} \mathrm{CD} 25^{-} \mathrm{T}$ cells with $\mathrm{CD} 40$-activated $\mathrm{B}$ cells without impairment of total CTLA- 4 production, and they ascribed the observed reduction to the strong recruitment of PI3K to the ICOS cytoplasmic domain, which competed with adaptor protein 2 (AP-2) to preferentially bind to mCTLA-4 (40). AP-2 is a critical factor to mediate CTLA-4 rapid endocytosis by targeting the YVNM motif on the cytoplasmic tail of CTLA-4, reduced combination of which with CTLA- 4 retains more CTLA4 proteins on the cell membrane (88). Additionally, ICOS has been suggested to be a pivotal marker of Tregs with a high capability to mediate CTLA-4-dependent transendocytosis, which is an important mechanism by which the activation signal can be attenuated by removing B7-1/B7-2 from opposing cells (89). In summary, ICOS expression plays a synergistic role for CTLA-4 to exert an inhibitory function of Tregs. The superior suppressive ability of ICOS ${ }^{+}$Tregs is likely owned to the higher CTLA-4 expression in part. Additionally, we have to note that as a co-inhibitory molecule, CTLA-4 can effectively inhibit ICOSproducing effector T cells, complicating the links between ICOS and CTLA-4 in fine-tuning the immune responses in diseases as well as under steady state conditions.

Recently, immune checkpoint therapy has demonstrated great clinical efficacy in the areas of anti-tumor treatment. Blocking the negative regulator of co-stimulation CTLA-4 is a feasible means by which to disrupt the immunosuppressive microenvironment in tumor tissue. The anti-CTLA-4 monoclonal antibody ipilimumab has been confirmed to have efficacy in treating multiple types of advanced tumors, such as gastric cancer, non-small cell lung cancer (NSCLC), metastatic melanoma, and urologic neoplasms. Furthermore, an increased proportion of IFN- $\gamma$-producing $\mathrm{CD}^{+}{ }^{+} \mathrm{ICOS}^{+} \mathrm{T}$ cells was sequentially observed in peripheral blood and tumor tissue after patients received anti-CTLA-4 therapy for bladder cancer, prostate tumors and metastatic melanoma, which was closely associated with clinical benefits and could serve as a specific pharmacodynamic indicator to monitor the efficacy of anti-CTLA-4 therapy (90-93). The benefits of this immunotherapy are a result of ICOS-activated PI3K signaling and T-bet expression that drives IFN- $\gamma$ secretion and changes the tumor suppressive immune microenvironment to a Th1 cell-dependent anti-tumor immune state (94). Based on this evidence, an anti-CTLA-4 antibody and ICOS agonist combination treatment may be an even better means of treating cancer. In addition, the frequency of $\mathrm{CD}^{+} \mathrm{ICOS}^{+} \mathrm{T}$ cells was also shown to be unexpectedly elevated in non-tumor tissues during treatment with CTLA-4 antibody, causing immunerelated adverse events, such as colitis, which should be improved in the future $(91,95)$.

\section{ICOS $^{+}$Tregs AND IMMUNE DISEASES}

The expression of ICOS has been observed to be upregulated in many autoimmune diseases, allergic diseases and different types of neoplasms. In some diseases, the upregulation of ICOS was most prominent in Tregs, and these $\mathrm{ICOS}^{+}$Tregs displayed a pivotal function in these diseases. Here, we briefly introduce the role of $\mathrm{ICOS}^{+}$Tregs in immune tolerance using several typical immune diseases as examples.

\section{ICOS $^{+}$Tregs and Type 1 Diabetes}

Type 1 diabetes (T1D) is a common autoimmune disease induced by $\mathrm{T}$ cell-dependent damage to insulin-producing islet beta cells. The NOD mouse strain is a classical model of autoimmune diseases that can spontaneously develop autoimmune diabetes 
and highly simulates the pathogenesis of T1D in human subjects (96). Through over 10 years of studies of diabetogenesis in NOD mice as well as type 1 diabetic patients, researchers have shown that the breakdown of immunological tolerance is a crucial step in the development of this disease, with Tregs being a major component mediating immunosuppression. Functional waning of Tregs in aged NOD mice was shown to result in an insufficient ability to control pathogenic Teff infiltration within pancreatic sites, leading to diabetogenic insulitis lesions and beta cell damage, although the number of nTregs did not decrease relative to that observed in T1D-resistant mice (97). The ineffectiveness of Tregs has also been confirmed in humans by observing their deficiency in suppressing Teff proliferation in vitro, with similar proportions of $\mathrm{CD}^{+}{ }^{+} \mathrm{CD} 25^{+} \mathrm{FOXP}^{+}$Tregs detected in agematched healthy individuals and type 1 diabetic subjects $(98,99)$. Due to the observed reduction in quality rather than quantity of Tregs, researches therefore wondered if there are differences in Tregs composition between T1D subjects and controls. Finally, after a great deal of investigation, T1D progression was shown to be correlated with the decrease in ICOS expression by intraislet Tregs (42). ICOS ${ }^{+}$Tregs, in contrast to ICOS ${ }^{-}$Tregs, were shown to be more proliferative and suppressive in situ, with a higher capacity to secrete IL-10 after islet-Ag stimulation. ICOS deficiency or Ag blockage impairs the competitive fitness of Tregs and fails to protect NOD mice from the onset of T1D (42, 100). Furthermore, Kornete et al. observed that ICOS $^{+}$ Tregs preferentially expressed CXCR3 in the pancreatic lymph node of prediabetic NOD mice, and this expression gave them a better migratory ability to home to $\beta$-islets (61). This discovery highlights the crucial role of ICOS from another perspective, as $\mathrm{CXCr}^{-/}$- NOD mice developed diabetes earlier than WT mice due to a decreased potential of these $C x c r 3^{-/-}$Treg cells to migrate from pancreatic lymph nodes to $\beta$-islets (101). Indeed, ICOS signaling is indispensable for the expression of CXCR3 on Tregs. Tregs from $\operatorname{Icos}^{-/}$NOD mice only express limited level of CXCR3 (61). These CXCR3-expressing ICOS ${ }^{+}$Tregs showed a Th1-like phenotype, with an increased expression of T-bet and IFN- $\gamma$ as well as its receptor IFN- $\gamma$ R, which enables ICOS ${ }^{+}$Tregs to respond to IFN- $\gamma$ produced by effector $\mathrm{T}$ cells and provides Tregs with an enhanced inhibitory ability (61).

In light of all of the evidence indicating the tremendous protective function of Tregs, particularly those that express ICOS, two therapeutic strategies have been suggested in the pathogenesis of T1D, and we will discuss below.

Low dose IL-2 supplementation or Il2 protective allelic variation was shown to be sufficient to release the local deficiency of IL-2 in pancreatic islets, increase the number of Tregs and rebalance the Treg-Teff cell ratio in inflamed islets, thereby preventing the onset or reversing established diabetes eventually (42, 102-104). This benefit of IL-2 therapy was partially contributed to by the augmented expansion of $\mathrm{ICOS}^{+}$Tregs in response to IL-2, which also imparted these regulatory cells with a higher anti-apoptotic and inhibitory function by promoting the expression of Bcl-2 and other Treg-associated proteins (CD25, CTLA-4, and GITR).

Another hotspot in diabetic treatment is the adoptive transfer of Tregs. The administration of autologous
$\mathrm{CD} 4{ }^{+} \mathrm{CD} 25^{\text {high }} \mathrm{CD} 127^{\text {low }}$ Tregs, which were isolated from the peripheral blood of the same individual and expanded ex vivo under polyclonal stimulation, to children with recent-onset of type 1 diabetes, dramatically increased C-peptide levels and decreased the dependency on exogenous insulin, demonstrating a safe and efficient therapy for T1D (105, 106). In addition, with the further development of this approach, researchers observed that Ag-specific Tregs could more efficiently suppress autoimmune diabetes than the blind amplified polyclonal Tregs in a NOD mouse model $(107,108)$. Recently, with the help of single-cell T cell receptor analysis and MHC tetramer staining, the specific antigens recognized by islet Tregs were finally discovered, among which, antigens corresponding to the top two islet Treg clones were insulin B:9-23 and proinsulin (109). This result also provides guidance for the selection of more effective Tregs for transfer. However, due to the rarity of Tregs specific to a particular islet antigen in the human Treg pool, obtaining enough Ag-specific Tregs is hardly realized in clinical practice as in animal experiments, where it is achievable to gain sufficient seed cells for expansion using TCR-transgenic mice. Therefore, a better means appears to be the use of the entire repertoire of isletspecific Tregs for expansion in actual treatment. Interestingly, by examining the distinct and restricted islet-specific Treg repertoire, researchers observed that the dominant clones highly expressed the TCR-dependent markers CD103, TIGIT, and ICOS, and markers of recent antigen exposure such as CD5 and Nur77 (109). Similarly, another study investigating a subset of tissue-specific Tregs with a high degree of self-reactivity, CD5 ${ }^{\text {hi }}$ Tregs, suggested that these highly self-reactive Tregs could provide significant protection against the development of diabetes (56). These CD5 $5^{\text {hi }}$ Tregs from infiltrated islets of NOD mice demonstrated an increased transcription of genes associated with TCR signaling, as well as those associated with an inhibitory function (Ctla-4, Icos, Lag3, and Tight), which seems to be highly associated with the characteristics of islet-specific Tregs (56). Therefore, it is not unreasonable to speculate that both methods identify the same functional Treg subset, which could provide a convenient means of obtaining therapeutic Tregs using a combination of several molecular markers for the treatment of diabetes, and even other autoimmune diseases. Additionally, before the use of adoptive cell transfer therapy, the stability of these Ag-specific Tregs should be taken into consideration, as Tregs may loss some stability after TCR activation and have a risk of transforming into pathogenic ex-Tregs (110). Perhaps adopting some approaches to promote Treg stability, such as using monoclonal antibody drugs to intervene Nrp1/PTEN/Foxo axis, prior to and/or following Treg adoptive transfer may be a good solution (110).

In summary, $\mathrm{ICOS}^{+}$Tregs are the primary cells in pancreatic islets involved in the prevention of diabetes, and any measures to expand these anti-inflammatory cells would efficiently treat diabetes.

\section{ICOS ${ }^{+}$Tregs and IBD}

Inflammatory bowel disease (IBD) is a chronic inflammatory disease characterized by the disruption of mucosal barrier 
function due to the dysbiosis of gut microbiota and unrestrained inflammatory responses mediated by effector $\mathrm{T}$ cells. Recent evidence has suggested that Tregs have a major role in the immune homeostasis of intestine and in the prevention of the development of IBD. For example, the transfer of $\mathrm{CD} 4{ }^{+} \mathrm{CD} 25^{+}$Tregs into mice with established inflammatory bowel disease, induced by injecting $\mathrm{CD}^{+}{ }^{+} \mathrm{CD} 45 \mathrm{RB}^{\text {high }} \mathrm{T}$ cells into severe combined immunodeficiency (SCID) mice, relieved wasting disease symptoms as well as infiltration of inflammatory cells (111).

To date, many therapeutic approaches have been shown to be effective against colitis in mouse models, most of which function by promoting the expansion and function of intestinal resident Tregs, especially ICOS-expressing Tregs. For instance, the injection of anti-CTLA-4 mAb was shown to ameliorate trinitrobenzene sulfonic acid (TNBS)-induced colitis by increasing indoleamine 2,3 dioxygenase (IDO) expression and inducing IL-10-producing ICOS $^{+}$Treg expansion in the mesenteric lymph nodes and inflamed colon (112). Besides that, the administration of galectin-3, which is limited in the inflamed intestinal epithelium of IBD patients but abundant in serum successfully suppressed the intense colonic inflammation induced by DSS or in a CD ${ }^{+} \mathrm{CD} 25^{-} \mathrm{T}$ cell transfer model (113). Careful inspection showed a superior suppressive function of Tregs induced by galectin-3, which promoted the expression of ICOS, PD-1, and FOXP3 on $\mathrm{CD}^{+}{ }^{+} \mathrm{T}$ cells in vitro in a dose-dependent manner (113). More recently, a study reported an interesting result where the adoptive transfer of $\mathrm{CD}^{+} 9^{+}$ Tregs could attenuate severe colitis in two mouse models (57). Furthermore, they suggested that the reason why CD69 ${ }^{+}$Tregs were more effective than $\mathrm{CD}^{-} 9^{-}$Tregs for the treatment of IBD was the high IL-10 production induced by CD69 in a c-Maf- and STAT3- dependent manner (57). Intriguingly, these CD69 ${ }^{+}$Tregs were resistant to Th17 polarization and exhibited high expression of the immunosuppression-associated markers CTLA-4, ICOS, CD38, and ICAM-1 (57). This outcome was consistent with the view that IL-10 secretion is associated with ICOS expression on Tregs. In addition, with increasing attention being paid to the intestinal microbiota, there is a great deal of evidence suggesting that many species of commensal microorganisms have a strong capability to affect the proliferation and function of colonic Tregs (114). Among these indigenous microorganisms, 46 mouse and 17 human strains belonging to Clostridia clusters IV, XIVa and XVIII have been shown to promote the accumulation and differentiation of Tregs in the colon lamina propria by providing a TGF$\beta$ - and IDO-enriched intestinal environment (115, 116). Oral inoculation of Clostridia strains attenuated the colitis of adult mice induced chemically or by the transfer of $\mathrm{CD} 4{ }^{+} \mathrm{CD} 45 \mathrm{RB}^{\text {hi }}$ $\mathrm{T}$ cells, providing another potential for treatment for IBD by rectifying bacterial dysbiosis $(115,116)$. Notably, most of the Clostridia-induced Tregs were helios ${ }^{-} \mathrm{ROR} \mathrm{t}^{+}$CTLA$4^{\text {hi }}$ ICOS $^{+}$IL- $10^{+}$Tregs.

Considering all of the above evidence, we speculate that ICOS could serve as a pivotal marker representing an indispensable subset of Tregs, at least those located in intestinal tissue, which are more suppressive and indicative of the positive outcome of
IBD. Landuyt et al. have confirmed that $\mathrm{ICOS}^{+}$but not ICOSdeficient Tregs could ameliorate active colitis, which is a strong corroboration of our point of view (14). Indeed, not only are $\mathrm{ICOS}^{+}$Tregs capable of maintaining $\mathrm{T}$ cell tolerance, various FOXP3 ${ }^{-}$regulatory $\mathrm{T}$ cells, such as $\operatorname{Tr} 1$ cells and Treg-of-B cells, which also express ICOS, can protect mice from experimental colitis (117). However, although ICOS appears to be beneficial by promoting the inhibitory ability of Tregs to assist in the prevention of IBD attacks, it was highly expressed on activated $\mathrm{CD}^{+}{ }^{+} \mathrm{T}$ cells after the onset of IBD (118). In addition, Kanai et al. have proved the therapeutic potential of anti-ICOS $\mathrm{mAb}$ in colitis induced by transfer of $\mathrm{CD}^{+}{ }^{+} \mathrm{CD} 45 \mathrm{RB}^{\text {hi }} \mathrm{T}$ cells to SCID mice (119). This paradox also gives us a warning that a comprehensive and careful measurement of the impact of ICOS on the overall immune environment, not just confined to Tregs or effector $\mathrm{T}$ cells, should be made before the selection of an ICOS agonist or antagonist for the treatment of one type of disease.

\section{ICOS ${ }^{+}$Tregs and Chronic Airway Inflammatory Diseases}

Elucidating the complicated interactions between various immune cells or between immune and structural cells and attempting to control the excessive immune responses and oversecretion of inflammatory mediators are key and difficult issues in the study of chronic airway inflammatory diseases, among which, chronic obstructive pulmonary disease (COPD) and asthma are two major diseases. Up to now, there was little knowledge regarding the importance of ICOS-related signals in COPD. Recently, we observed an increased proportion of ICOS in $\mathrm{CD}^{+}{ }^{+} \mathrm{CD} 25^{+} \mathrm{FOXP}^{+}$Tregs of COPD patients, yet the details of the function of this molecule remains to be studied (120). Herein, we emphatically introduce ICOS-associated signals in asthma.

Asthma is an airway hyperreactive disease mediated by type 2 immunity characterized by airway eosinophilic inflammation, mucus hypersecretion, high type 2 cytokines secretion and increased $\lg \mathrm{E}$ antibody titers. $\mathrm{T}$ cell tolerance is the primary mechanism protecting human from the development of this disease. Numerous recent studies have revealed that Tregs and ICOS-ICOSL signals are highly involved in the antiinflammatory process against asthma $(39,121)$. The percentage of $\mathrm{ICOS}^{+}$Tregs was shown to be increased in the lungs of OVAtolerized mice, and they exerted a strong capacity to inhibit Th2-mediated immune responses (91). ICOS deficiency was observed to restrain the suppressive ability of Tregs in controlling asthma, as the transfer of $I \cos ^{-/-}$Tregs into OVA-sensitized recipients could not suppress the severe allergic phenotype (91). Moreover, compared to $\mathrm{WT}$ mice, $I \cos ^{-1-}$ mice were unable to generate an equal number of $\mathrm{FOXP}^{+}$Tregs in the lungs, indicating a potent proliferation-promoting effect mediated by ICOS signaling other than enhancing the inhibitory ability of Tregs (91). More importantly, ICOS signaling was reported to be widely involved in the induction of respiratory tolerance. Blockage of the ICOS signaling pathway in the induction stage of the immune tolerance of OVA-challenged mice impaired the development of respiratory tolerance $(39,121)$. This effect of the 
induction of tolerance was partly attributed to lung plasmacytoid DCs, which were shown to produce IL-10 and express high levels of ICOSL, as well as having the ability to induce Treg generation (121-123). A deficiency of ICOS in CD $4^{+}$T cells or pretreatment of DCs with anti-ICOSL mAb both abolished the ability of DCs to induce $\mathrm{T}$ cell tolerance ex vivo and in an adoptive transfer model (36). Furthermore, several studies regarding Fms-like tyrosine kinase 3 ligand (Flt3-L), which can reverse allergen-induced mouse models of asthma, demonstrated that Flt3-L not only increases the number of $\mathrm{CD}^{+}{ }^{+} \mathrm{CD} 25^{+} \mathrm{FOXP}^{+} \mathrm{IL}-10^{+} \mathrm{ICOS}^{+}$ Tregs but also recruits more $\mathrm{CD} 11 \mathrm{c}^{\text {high }} \mathrm{CD} 11 \mathrm{~b}^{\text {low }} \mathrm{DCs}$ to the lung of OVA-sensitized mice, both of which worked synergistically to attenuate AHR through the reinforced interaction between ICOS and ICOSL $(124,125)$.

Apart from the interaction of ICOS and ICOSL between DCs and Tregs, the interaction between Tregs and ILC2 is also important in the suppression of allergens. As is reported, group 2 innate lymphoid cells (ILC2s), which resemble Th2 cells, are capable of producing copious amounts of the type 2 cytokines IL5 and IL-13 and are responsible for the development of allergic respiratory inflammation (126). The co-expression of ICOS and ICOSL on ILC2s promotes the homeostasis and function of these cells in a cis and trans formation, exaggerating the inflammatory responses (127, 128). In contrast, ICOS expressed on Tregs could occupy ICOSL on ILC2s, restricting the cis communication among ILC2s and leading to decreased cytokine production by ILC2s $(127,128)$. With the assistance of the suppressive cytokines TGF- $\beta$ and IL-10, Tregs were shown to powerfully attenuate airway hyperreactivity induced by ILC2 in an ICOS:ICOSL cellto-cell contact manner $(127,128)$.

Moreover, emerging evidence has shown that IL-35 produced by $\mathrm{ICOS}^{+}$Tregs can suppress IL-17-dependent airway hyperresponsiveness, which is another synergetic mechanism contributing to allergic asthma (129). Overall, ICOS $^{+}$Tregs work with multiple types of immune cells to establish immune tolerance to asthma, which demonstrates their utility as a therapeutic or in the strategies for the prevention of allergic airway diseases. However, it should also be noticed that divergent outcomes could be caused by intervention of the ICOS pathway at different time points in the course of asthma. The blockade of ICOS co-stimulation was shown to attenuate Th2-mediated airway inflammation in an allergic mouse model after mice were sensitized and challenged to an allergen, while they showed symptoms comparable to allergic mice, such as aggravated eosinophil infiltration, Th2 cytokine secretion and mucus hypersecretion, if these mice received anti-ICOSL mAb in the induction stage of immune tolerance $(39,130)$. Therefore, both the intervention time and overall understanding of a particular disease are necessary concerns if applying drugs or other means to interfere with ICOS signaling for treatment.

\section{ICOS $^{+}$Tregs and Other Autoimmune Diseases}

In addition to the three diseases mentioned above, there are other diseases with high ICOS expression on Tregs, including systemic lupus erythematosus (SLE), rheumatoid arthritis (RA), sarcoidosis (131-133). The increased frequency of $\mathrm{ICOS}^{+}$Tregs has been shown to have practical significance in these diseases. For example, the elevated frequency of $\mathrm{ICOS}^{+}$Tregs was observed to show a positive correlation with SLE disease activity index scores and the serum antibody titer of anti-dsDNA, although the authors suggested that these $\mathrm{ICOS}^{+}$Tregs might be precursor inflammatory cells (131). In addition, it was also demonstrated to serve as a predictor of responses to treatment, as a significantly larger proportion of $\mathrm{ICOS}^{+}$Tregs and skewed type 2 responses were observed in MTX-non-responsive RA patients (132). Moreover, Sakthivel and colleagues reported high expression levels of ICOS in lung Tregs of pulmonary sarcoidosis patients, and it was particularly high in patients with Lofgren's syndrome (LS) compared with NLS, thus associating the degree of ICOS expression on Tregs with prognosis of sarcoidosis (133). In summary, the abnormal frequency of ICOS $^{+}$Tregs could be a potential biomarker in the assessment of prognosis and the effectiveness of specific treatment regimens.

\section{ICOS ${ }^{+}$Tregs and Malignant Tumors}

In contrast to most autoimmune diseases or allergic diseases, Tregs infiltrated in tumor tissues consistently impede effector $\mathrm{T}$ cell-mediated anti-tumor responses, inhibiting the treatment of tumors. $\mathrm{ICOS}^{+}$Tregs, which were suggested to have a potent suppressive ability compared with their $\mathrm{ICOS}^{-}$counterpart, therefore, play a dominant role in the process of immune escape. Recently, with a growing numbers of studies focusing on the immunophenotype of TILs, an increased percentage of $\mathrm{ICOS}^{+}$Tregs have been observed in more and more types of tumor tissues, including melanoma, (134) head and neck squamous cell cancers, (135) gastric cancers, (136) breast cancer, (137) ovarian cancer, (138) clear cell renal cell carcinoma, (139) and acute myeloid leukemia (AML) (140). Furthermore, the elevated proportion of ICOS ${ }^{+}$Tregs was shown to be associated with a bad outcome in most cases, and it was indicated as a better predictor of prognosis than the percentage of total Tregs under some circumstances. For instance, Nagase et al. observed an increased expression of ICOS in $\mathrm{CD} 4^{+} \mathrm{FOXP}^{+}$TILs with the increase in the stage of gastric cancers, and the elevated expression of ICOS in $\mathrm{CD} 4^{+} \mathrm{FOXP}^{+}$TILs was negatively correlated with relapse-free survival time (136). AML patients with high frequency of ICOS $^{+}$Tregs have an evidently shorter overall survival and disease-free survival relative to those of low ICOS $^{+}$Treg group (140). Moreover, an enhanced expansion of $\mathrm{ICOS}^{+}$Tregs in patients with melanoma after the first cycle of high-dose IL-2 therapy was identified to be associated with unfavorable prognosis (141). In addition, the expression of ICOSL in malignant tumor cells or tumor-associated pDCs was confirmed to be a good booster for the accumulation of ICOS $^{+}$Tregs in some tumor tissues $(137,140,142)$. Thus, the interaction between ICOS and ICOSL is a central mechanism in tumor immune evasion, although there are still other cancer types with higher levels of ICOS expression on activated effector TILs other than Tregs, in which ICOS expression was correlated with improved survival, such as in colorectal cancer (143) and lung adenocarcinoma (144). 


\section{ICOS-ASSOCIATED THERAPEUTIC APPLICATIONS IN IMMUNE DISEASES}

Currently, various monoclonal antibodies have been developed to intervene the overactive ICOS-ICOSL interaction. At present, there are six anti-ICOS monoclonal antibodies [JTX-2011 (NCT04319224), GSK3359609 (NCT04128696), vopratelimab (NCT04319224), BMS-986226 (NCT03251924), MEDI-570 (NCT02520791), and KY1044 (NCT03829501)] and three anti-ICOSL mAbs [AMG-557 (NCT01683695), AMG570 (NCT04058028), and ALPN-101 (NCT04227938)] on the market or in clinical trials. Treatment with anti-ICOS agonistic mAb or anti-ICOS antagonistic $\mathrm{mAb}$ to treat cancers by enhancing the function of effector $\mathrm{T}$ cells and/or depleting ICOS ${ }^{\text {hi }}$ Tregs alone or in combination with other monoclonal antibodies such as nivolumab and ipilimumab has achieved great success and has been a hot spot in cancer immunotherapy (145). For example, KY1044 can preferentially deplete ICOS ${ }^{\text {high }}$ Tregs via antibody dependent cell-mediated cytotoxicity (ADCC) and stimulate $\mathrm{ICOS}^{+} \mathrm{T}$ effector cells to exhibit anti-tumor responses (146). Furthermore, some bispecific antibodies are currently being developed, including XmAb23104 (NCT03752398) and KY1055 (146), which simultaneously target ICOS/PD-1 or ICOS/PD-L1, respectively, potentially delivering a stronger anti-tumor response.

Except for these innovating monoclonal antibodies, there are other therapeutic schedules available depending on the ICOSICOSL pathway. The CAR with the ICOS-4-1BB fusing protein increased CAR-T cell persistence in vivo and anti-tumor efficacy (147). Additionally, a technology using a ${ }^{89} \mathrm{Zr}$-DFO-ICOS mAb as a probe for PET imaging was developed as a non-invasive strategy to monitor or allow for the early prediction of therapeutic responses by quantifying the number of $\mathrm{ICOS}^{+}$activated T cells in a Lewis lung cancer model (148). In other words, there is great potentiality for the use of ICOS as a therapeutic target in the treatment of tumors.

For autoimmune diseases, the use of ICOS as a therapeutic target is still being explored. Despite the application of drugs to increase the proportion of $\mathrm{ICOS}^{+}$Tregs or the adoptive transfer of Tregs having been shown to be therapeutic in mouse models, these treatments still have a long way to go to be put into clinical use, partly because of the technical difficulty and high cost of adoptive transfer therapy. Anti-ICOS/ICOSL mAb treatment may be a potential therapeutic option for some refractory or severe autoimmune diseases. At present, there are some phase I/II clinical trials of anti-ICOSL monoclonal antibody drugs to treat autoimmune diseases, such as on SLE, RA, psoriasis, and primary Sjögren's syndrome. For example, AMG557 has been used for SLE treatment and shows safety and potential efficacy for this disease $(149,150)$. Yet a great deal of research needs to be performed before these monoclonal antibody drugs are applied to the clinic.

\section{REFERENCES}

1. Hutloff A, Dittrich AM, Beier KC, Eljaschewitsch B, Kraft R, Anagnostopoulos I, et al. ICOS is an inducible T-cell co-stimulator structurally and functionally related to CD28. Nature. (1999) 397:263-6. doi: $10.1038 / 16717$
Additionally, it should be noted that both ICOS monoclonal antibody treatment and other therapeutic schedules act on the total ICOS signaling, rather than Treg-specific ICOS signaling. But the benefits of ICOS immunotherapy can be partly gained either by limiting $\operatorname{ICOS}^{+}$Treg expansion and function in cancer diseases or by enhancing Treg immunoregulatory capacity in autoimmune diseases, although they could also be obtained by regulating effector $\mathrm{T}$ cells or Tfh cells, which depends on different drug mechanisms and context conditions. Different monoclonal antibodies can function through different mechanisms, affecting either effector $\mathrm{T}$ cells or Tregs, and diverse disease conditions should also be taken into consideration in the selection of monoclonal antibodies.

\section{CONCLUSION}

The ICOS signaling pathway is widely involved in immune responses, indicating an activated state for immune cells in general. Despite exerting pro-inflammatory effect in effector $\mathrm{T}$ cells, ICOS signaling is also highly involved in anti-inflammatory responses, and this involvement is primarily mediated by Tregs. The results of many recent studies have suggested that ICOS ${ }^{+}$ Tregs are an activated subset with strong inhibitory ability that can prevent the onset or restrain the progression of most autoimmune and allergic diseases, while they can also contribute to the immunosuppression of tumors. Sufficient evidence has demonstrated that $\mathrm{ICOS}^{+}$Tregs can serve as a biomarker for clinical outcome and be used in testing therapeutic responses, not only in autoimmune diseases but also in tumors. However, due to the complex and comprehensive effects of ICOS to immune cells, which are not limited to Tregs, a thorough understanding of the essential role of ICOS in Tregs and its complicated function to the overall immune system before treatment would be conducive to the formulation of rational strategies to manipulate ICOS signals, such as in the selection of appropriate anti-ICOS/ICOSL monoclonal antibody drugs.

\section{AUTHOR CONTRIBUTIONS}

D-YL wrote the manuscript. X-ZX conceived the idea and revised the manuscript. All authors contributed to the article and approved the submitted version.

\section{ACKNOWLEDGMENTS}

The authors appreciate BioRender.com for the convenience of the creation of figures.
2. Greenwald RJ, Freeman GJ, Sharpe AH. The B7 family revisited. Annu Rev Immunol. (2005) 23:515-48. doi: 10.1146/annurev.immunol.23.021704. 115611

3. Ling V, Wu PW, Finnerty HF, Bean KM, Spaulding V, Fouser LA, et al. Cutting edge: identification of GL50, a novel B7like protein that functionally binds to ICOS receptor. $J$ 
Immunol. (2000) 164:1653-7. doi: 10.4049/jimmunol.164.4. 1653

4. Kunicki MA, Amaya Hernandez LC, Davis KL, Bacchetta R, Roncarolo MG. Identity and diversity of human peripheral $\mathrm{Th}$ and $\mathrm{T}$ regulatory cells defined by single-cell mass cytometry. J Immunol. (2018) 200:336-46. doi: 10.4049/ jimmunol.1701025

5. Simoni Y, Fehlings M, Kløverpris HN, McGovern N, Koo S-L, Loh CY, et al. Human innate lymphoid cell subsets possess tissue-type based heterogeneity in phenotype and frequency. Immunity. (2017) 46:148-61. doi: 10.1016/j. immuni.2016.11.005

6. Fonseca VR, Ribeiro F, Graca L. T follicular regulatory (Tfr) cells: dissecting the complexity of Tfr-cell compartments. Immunol Rev. (2019) 288:112-27. doi: 10.1111/imr.12739

7. Wikenheiser DJ, Stumhofer JS. ICOS co-stimulation: friend or foe? Front Immunol. (2016) 7:304. doi: 10.3389/fimmu.2016.00304

8. Löhning M, Hutloff A, Kallinich T, Mages HW, Bonhagen K, Radbruch A, et al. Expression of ICOS in vivo defines CD4+effector T cells with high inflammatory potential and a strong bias for secretion of interleukin 10. J Exp Med. (2003) 197:181-93. doi: 10.1084/jem.20020632

9. Ito T, Hanabuchi S, Wang YH, Park WR, Arima K, Bover L, et al. Two functional subsets of FOXP3+ regulatory T cells in human thymus and periphery. Immunity. (2008) 28:870-80. doi: 10.1016/j.immuni.2008. 03.018

10. Duhen T, Duhen R, Lanzavecchia A, Sallusto F, Campbell DJ. Functionally distinct subsets of human FOXP3+ Treg cells that phenotypically mirror effector Th cells. Blood. (2012) 119:4430-40. doi: 10.1182/blood-2011-11392324

11. Nazzal D, Gradolatto A, Truffault F, Bismuth J, Berrih-Aknin S. Human thymus medullary epithelial cells promote regulatory T-cell generation by stimulating interleukin-2 production via ICOS ligand. Cell Death Dis. (2014) 5:e1420. doi: 10.1038/cddis.2014.377

12. Smigiel KS, Richards E, Srivastava S, Thomas KR, Dudda JC, Klonowski KD, et al. CCR7 provides localized access to IL-2 and defines homeostatically distinct regulatory T cell subsets. J Exp Med. (2014) 211:121-36. doi: 10.1084/ jem.20131142

13. Vocanson M, Rozieres A, Hennino A, Poyet G, Gaillard V, Renaudineau $\mathrm{S}$, et al. Inducible costimulator (ICOS) is a marker for highly suppressive antigen-specific $\mathrm{T}$ cells sharing features of TH17/TH1 and regulatory $\mathrm{T}$ cells. J Allergy Clin Immunol. (2010) 126:280-9, 289.e1-7. doi: 10.1016/j.jaci.2010. 05.022

14. Landuyt AE, Klocke BJ, Colvin TB, Schoeb TR, Maynard CL. Cutting edge: ICOS-deficient regulatory $\mathrm{T}$ cells display normal induction of but readily downregulate expression of Foxp3. J Immunol. (2019) 202:1039-44. doi: 10.4049/jimmunol.1801266

15. Joller N, Lozano E, Burkett PR, Patel B, Xiao S, Zhu C, et al. Treg cells expressing the coinhibitory molecule TIGIT selectively inhibit proinflammatory Th1 and Th17 cell responses. Immunity. (2014) 40:569-81. doi: 10.1016/j.immuni.2014.02.012

16. Cretney E, Xin A, Shi W, Minnich M, Masson F, Miasari M, et al. The transcription factors Blimp-1 and IRF4 jointly control the differentiation and function of effector regulatory T cells. Nat Immunol. (2011) 12:304-11. doi: $10.1038 /$ ni.2006

17. Zheng Y, Chaudhry A, Kas A, deRoos P, Kim JM, Chu T-T, et al. Regulatory T-cell suppressor program co-opts transcription factor IRF4 to control T(H)2 responses. Nature. (2009) 458:351-6. doi: 10.1038/nature07674

18. Koizumi S-I, Sasaki D, Hsieh T-H, Taira N, Arakaki N, Yamasaki S, et al. JunB regulates homeostasis and suppressive functions of effector regulatory $\mathrm{T}$ cells. Nat Commun. (2018) 9:5344. doi: 10.1038/s41467-018-07735-4

19. Grinberg-Bleyer Y, Oh H, Desrichard A, Bhatt DM, Caron R, Chan TA, et al. NF- $\mathrm{\kappa B}$ c-Rel is crucial for the regulatory $\mathrm{T}$ cell immune checkpoint in cancer. Cell. (2017) 170:1096-108.e13. doi: 10.1016/j.cell.2017.08.004

20. Oh H, Grinberg-Bleyer Y, Liao W, Maloney D, Wang P, Wu Z, et al. An NF$\kappa \mathrm{B}$ transcription-factor-dependent lineage-specific transcriptional program promotes regulatory T cell identity and function. Immunity. (2017) 47:45065.e5. doi: 10.1016/j.immuni.2017.08.010

21. Vasanthakumar A, Liao Y, Teh P, Pascutti MF, Oja AE, Garnham AL, et al. The TNF receptor superfamily-NF- $\mathrm{\kappa B}$ axis is critical to maintain effector regulatory T cells in lymphoid and non-lymphoid tissues. Cell Rep. (2017) 20:2906-20. doi: 10.1016/j.celrep.2017.08.068

22. Ziegler SF. FOXP3: not just for regulatory T cells anymore. Eur J Immunol. (2007) 37:21-3. doi: 10.1002/eji.200636929

23. Wang J, Ioan-Facsinay A, van der Voort EI, Huizinga TW, Toes RE. Transient expression of FOXP3 in human activated nonregulatory CD4+ T cells. Eur J Immunol. (2007) 37:129-38. doi: 10.1002/eji.200636435

24. Koch MA, Tucker-Heard G, Perdue NR, Killebrew JR, Urdahl KB, Campbell DJ. The transcription factor T-bet controls regulatory $\mathrm{T}$ cell homeostasis and function during type 1 inflammation. Nat Immunol. (2009) 10:595-602. doi: 10.1038/ni.1731

25. Yu F, Sharma S, Edwards J, Feigenbaum L, Zhu J. Dynamic expression of transcription factors T-bet and GATA-3 by regulatory T cells maintains immunotolerance. Nat Immunol. (2015) 16:197-206. doi: 10.1038/ni.3053

26. Levine AG, Mendoza A, Hemmers S, Moltedo B, Niec RE, Schizas M, et al. Stability and function of regulatory $\mathrm{T}$ cells expressing the transcription factor T-bet. Nature (2017) 546:421-5. doi: 10.1038/nature22360

27. Yang BH, Hagemann S, Mamareli P, Lauer U, Hoffmann U, Beckstette $\mathrm{M}$, et al. Foxp3(+) T cells expressing ROR $\gamma$ t represent a stable regulatory T-cell effector lineage with enhanced suppressive capacity during intestinal inflammation. Mucosal Immunol. (2016) 9:444-57. doi: 10.1038/mi. 2015.74

28. Sefik E, Geva-Zatorsky N, Oh S, Konnikova L, Zemmour D, McGuire AM, et al. Mucosal Immunology. Individual intestinal symbionts induce a distinct population of ROR $\gamma^{+}$regulatory T cells. Science. (2015) 349:993-7. doi: 10.1126/science.aaa9420

29. Ohnmacht C, Park J-H, Cording S, Wing JB, Atarashi K, Obata Y, et al. Mucosal immunology. The microbiota regulates type 2 immunity through ROR $\gamma \mathrm{t}^{+}$T cells. Science. (2015) 349:989-93. doi: 10.1126/science.aac4263

30. Zhou X, Bailey-Bucktrout SL, Jeker LT, Penaranda C, Martínez-Llordella $\mathrm{M}$, Ashby $\mathrm{M}$, et al. Instability of the transcription factor Foxp3 leads to the generation of pathogenic memory T cells in vivo. Nat Immunol. (2009) 10:1000-7. doi: 10.1038/ni.1774

31. Feng T, Cao AT, Weaver CT, Elson CO, Cong Y. Interleukin- 12 converts Foxp3+ regulatory $\mathrm{T}$ cells to interferon- $\gamma$-producing Foxp3+ T cells that inhibit colitis. Gastroenterology. (2011) 140:2031-43. doi: 10.1053/j.gastro. 2011.03.009

32. Zheng Y, Josefowicz S, Chaudhry A, Peng XP, Forbush K, Rudensky AY. Role of conserved non-coding DNA elements in the Foxp3 gene in regulatory T-cell fate. Nature. (2010) 463:808-12. doi: 10.1038/nature08750

33. Bovenschen HJ, van de Kerkhof PC, van Erp PE, Woestenenk R, Joosten I, Koenen HJ. Foxp3+ regulatory T cells of psoriasis patients easily differentiate into IL-17A-producing cells and are found in lesional skin. J Invest Dermatol. (2011) 131:1853-60. doi: 10.1038/jid.2011.139

34. Zhang Z, Zhang W, Guo J, Gu Q, Zhu X, Zhou X. Activation and functional specialization of regulatory $\mathrm{T}$ cells lead to the generation of Foxp3 instability. J Immunol. (2017) 198:2612-25. doi: 10.4049/jimmunol.1601409

35. Huynh A, DuPage M, Priyadharshini B, Sage PT, Quiros J, Borges CM, et al. Control of PI(3) kinase in Treg cells maintains homeostasis and lineage stability. Nat Immunol. (2015) 16:188-96. doi: 10.1038/ni.3077

36. Tuettenberg A, Huter E, Hubo M, Horn J, Knop J, Grimbacher B, et al. The role of ICOS in directing $\mathrm{T}$ cell responses: ICOS-dependent induction of T cell anergy by tolerogenic dendritic cells. J Immunol. (2009) 182:3349-56. doi: 10.4049/jimmunol.0802733

37. Jonuleit H, Schmitt E, Steinbrink K, Enk AH. Dendritic cells as a tool to induce anergic and regulatory T cells. Trends Immunol. (2001) 22:394-400. doi: 10.1016/s1471-4906(01)01952-4

38. Burmeister Y, Lischke T, Dahler AC, Mages HW, Lam KP, Coyle AJ, et al. ICOS controls the pool size of effector-memory and regulatory T cells. $J$ Immunol. (2008) 180:774-82. doi: 10.4049/jimmunol.180.2.774

39. Busse M, Krech M, Meyer-Bahlburg A, Hennig C, Hansen G. ICOS mediates the generation and function of $\mathrm{CD} 4+\mathrm{CD} 25+\mathrm{Foxp} 3+$ regulatory $\mathrm{T}$ cells conveying respiratory tolerance. J Immunol. (2012) 189:1975-82. doi: 10. 4049/jimmunol.1103581

40. Zheng J, Chan PL, Liu Y, Qin G, Xiang Z, Lam KT, et al. ICOS regulates the generation and function of human CD4+ Treg in a CTLA-4 dependent manner. PLoS One. (2013) 8:e82203. doi: 10.1371/journal.pone.0082203 
41. Chen Q, Mo L, Cai X, Wei L, Xie Z, Li H, et al. ICOS signal facilitates Foxp3 transcription to favor suppressive function of regulatory T cells. Int J Med Sci. (2018) 15:666-73. doi: 10.7150/ijms.23940

42. Kornete M, Sgouroudis E, Piccirillo CA. ICOS-dependent homeostasis and function of Foxp3+ regulatory T cells in islets of nonobese diabetic mice. $J$ Immunol. (2012) 188:1064-74. doi: 10.4049/jimmunol.1101303

43. Chen Y, Shen S, Gorentla BK, Gao J, Zhong XP. Murine regulatory T cells contain hyperproliferative and death-prone subsets with differential ICOS expression. J Immunol. (2012) 188:1698-707. doi: 10.4049/jimmunol. 1102448

44. Redpath SA, van der Werf N, Cervera AM, MacDonald AS, Gray D, Maizels RM, et al. ICOS controls Foxp3(+) regulatory T-cell expansion, maintenance and IL-10 production during helminth infection. Eur J Immunol. (2013) 43:705-15. doi: 10.1002/eji.201242794

45. Chougnet CA, Tripathi P, Lages CS, Raynor J, Sholl A, Fink P, et al. A major role for Bim in regulatory T cell homeostasis. J Immunol. (2011) 186:156-63. doi: 10.4049/jimmunol.1001505

46. Raynor J, Karns R. IL- 6 and ICOS antagonize bim and promote regulatory T cell accrual with age. J Immunol. (2015) 195:944-52. doi: 10.4049/jimmunol. 1500443

47. Pierson W, Cauwe B, Policheni A, Schlenner SM, Franckaert D, Berges J, et al. Antiapoptotic Mcl-1 is critical for the survival and niche-filling capacity of Foxp $3^{+}$regulatory T cells. Nat Immunol. (2013) 14:959-65. doi: 10.1038/ni. 2649

48. Ahmad S, Abu-Eid R, Shrimali R, Webb M, Verma V, Doroodchi A, et al. Differential PI3Kdelta signaling in CD4(+) T-cell subsets enables selective targeting of T regulatory cells to enhance cancer immunotherapy. Cancer Res. (2017) 77:1892-904. doi: 10.1158/0008-5472.CAN-16-1839

49. Chinen T, Kannan AK, Levine AG, Fan X, Klein U, Zheng Y, et al. An essential role for the IL-2 receptor in T cell function. Nat Immunol. (2016) 17:1322-33. doi: $10.1038 /$ ni.3540

50. Liu Z, Gerner MY, Van Panhuys N, Levine AG, Rudensky AY, Germain RN. Immune homeostasis enforced by co-localized effector and regulatory $\mathrm{T}$ cells. Nature. (2015) 528:225-30. doi: 10.1038/nature16169

51. Kohyama M, Sugahara D, Sugiyama S, Yagita H, Okumura K, Hozumi N. Inducible costimulator-dependent IL-10 production by regulatory T cells specific for self-antigen. Proc Natl Acad Sci USA. (2004) 101:4192-7. doi: 10.1073/pnas.0400214101

52. Shalaby KH, Jo T, Nakada E, Allard-Coutu A, Tsuchiya K, Hirota N, et al. ICOS-expressing CD4 T cells induced via TLR4 in the nasal mucosa are capable of inhibiting experimental allergic asthma. J Immunol. (2012) 189:2793-804. doi: 10.4049/jimmunol.1201194

53. O’Brien CA, Batista SJ, Still KM, Harris TH. IL- 10 and ICOS differentially regulate $\mathrm{T}$ cell responses in the brain during chronic toxoplasma gondii infection. J Immunol. (2019) 202:1755-66. doi: 10.4049/jimmunol.1801229

54. Kühn R, Löhler J, Rennick D, Rajewsky K, Müller W. Interleukin-10-deficient mice develop chronic enterocolitis. Cell. (1993) 75:263-74.

55. Rubtsov YP, Rasmussen JP, Chi EY, Fontenot J, Castelli L, Ye X, et al. Regulatory $\mathrm{T}$ cell-derived interleukin-10 limits inflammation at environmental interfaces. Immunity. (2008) 28:546-58. doi: 10.1016/j. immuni.2008.02.017

56. Sprouse ML, Scavuzzo MA, Blum S, Shevchenko I, Lee T, Makedonas G, et al. High self-reactivity drives T-bet and potentiates Treg function in tissuespecific autoimmunity. JCI Insight. (2018) 3:e97322. doi: 10.1172/jci.insight. 97322

57. Yu L, Yang F, Zhang F, Guo D, Li L, Wang X, et al. CD69 enhances immunosuppressive function of regulatory T-cells and attenuates colitis by prompting IL-10 production. Cell Death Dis. (2018) 9:905. doi: 10.1038/ s41419-018-0927-9

58. Cibrian D, Sanchez-Madrid F. CD69: from activation marker to metabolic gatekeeper. Eur J Immunol. (2017) 47:946-53. doi: 10.1002/eji.201646837

59. Anderson AC, Joller N, Kuchroo VK. Lag-3, Tim-3, and TIGIT: co-inhibitory receptors with specialized functions in immune regulation. Immunity. (2016) 44:989-1004. doi: 10.1016/j.immuni.2016.05.001

60. Moore TV, Clay BS, Cannon JL, Histed A, Shilling RA, Sperling AI. Inducible costimulator controls migration of $\mathrm{T}$ cells to the lungs via down-regulation of CCR7 and CD62L. Am J Respir Cell Mol Biol. (2011) 45:843-50. doi: 10.1165/rcmb.2010-0466OC
61. Kornete M, Mason ES, Girouard J, Lafferty EI, Qureshi S, Piccirillo CA. Th1-Like ICOS+ Foxp3+ Treg cells preferentially express CXCR3 and home to $\beta$-Islets during pre-diabetes in BDC2.5 NOD mice. PLoS One. (2015) 10:e0126311. doi: 10.1371/journal.pone.0126311

62. Nakanishi Y, Ikebuchi R, Chtanova T, Kusumoto Y, Okuyama H, Moriya T, et al. Regulatory $\mathrm{T}$ cells with superior immunosuppressive capacity emigrate from the inflamed colon to draining lymph nodes. Mucosal Immunol. (2018) 11:437-48. doi: 10.1038/mi.2017.64

63. Chien $\mathrm{CH}$, Chiang BL. Regulatory $\mathrm{T}$ cells induced by $\mathrm{B}$ cells: a novel subpopulation of regulatory T cells. J Biomed Sci. (2017) 24:86. doi: 10.1186/ s12929-017-0391-3

64. Okkenhaug K, Vanhaesebroeck B. PI3K in lymphocyte development, differentiation and activation. Nat Rev Immunol. (2003) 3:317-30. doi: 10. 1038/nri1056

65. Chi H. Regulation and function of mTOR signalling in T cell fate decisions. Nat Rev Immunol. (2012) 12:325-38. doi: 10.1038/nri3198

66. Zeng H, Yang K, Cloer C, Neale G, Vogel P, Chi H. mTORC1 couples immune signals and metabolic programming to establish T(reg)-cell function. Nature. (2013) 499:485-90. doi: 10.1038/nature12297

67. Battaglia M, Stabilini A, Roncarolo M-G. Rapamycin selectively expands CD4+CD25+FoxP3+ regulatory T cells. Blood. (2005) 105:4743-8.

68. Delgoffe GM, Kole TP, Zheng Y, Zarek PE, Matthews KL, Xiao B, et al. The mTOR kinase differentially regulates effector and regulatory $\mathrm{T}$ cell lineage commitment. Immunity. (2009) 30:832-44. doi: 10.1016/j.immuni.2009. 04.014

69. Xu L, Huang Q, Wang H, Hao Y, Bai Q, Hu J, et al. The kinase mTORC1 promotes the generation and suppressive function of follicular regulatory $\mathrm{T}$ cells. Immunity. (2017) 47:538-51.e5. doi: 10.1016/j.immuni.2017.08.011

70. Chang J-H, Hu H, Jin J, Puebla-Osorio N, Xiao Y, Gilbert BE, et al. TRAF3 regulates the effector function of regulatory $\mathrm{T}$ cells and humoral immune responses. J Exp Med. (2014) 211:137-51. doi: 10.1084/jem.20131019

71. Shrestha S, Yang K, Guy C, Vogel P, Neale G, Chi H. Treg cells require the phosphatase PTEN to restrain TH1 and TFH cell responses. Nat Immunol. (2015) 16:178-87. doi: 10.1038/ni.3076

72. Sharma MD, Shinde R, McGaha TL, Huang L, Holmgaard RB, Wolchok JD, et al. The PTEN pathway in Tregs is a critical driver of the suppressive tumor microenvironment. Sci Adv. (2015) 1:e1500845. doi: 10.1126/sciadv.1500845

73. Coyle AJ, Lehar S, Lloyd C, Tian J, Delaney T, Manning S, et al. The CD28related molecule ICOS is required for effective $\mathrm{T}$ cell-dependent immune responses. Immunity. (2000) 13:95-105. doi: 10.1016/s1074-7613(00) 00011-x

74. Fos C, Salles A, Lang V, Carrette F, Audebert S, Pastor S, et al. ICOS ligation recruits the p50 PI3K regulatory subunit to the immunological synapse. $J$ Immunol. (2008) 181:1969-77. doi: 10.4049/jimmunol.181.3.1969

75. Harada Y, Ohgai D, Watanabe R, Okano K, Koiwai O, Tanabe K, et al. A single amino acid alteration in cytoplasmic domain determines IL-2 promoter activation by ligation of CD28 but not inducible costimulator (ICOS). J Exp Med. (2003) 197:257-62. doi: 10.1084/jem.20021305

76. Arimura Y, Kato H, Dianzani U, Okamoto T, Kamekura S, Buonfiglio D, et al. A co-stimulatory molecule on activated T cells, H4/ICOS, delivers specific signals in $\mathrm{T}(\mathrm{h})$ cells and regulates their responses. Int Immunol. (2002) 14:555-66. doi: 10.1093/intimm/dxf022

77. Peach RJ, Bajorath J, Brady W, Leytze G, Greene J, Naemura J, et al. Complementarity determining region 1 (CDR1)- and CDR3-analogous regions in CTLA-4 and CD28 determine the binding to B7-1. J Exp Med. (1994) 180:2049-58. doi: 10.1084/jem.180.6.2049

78. Logue EC, Bakkour S, Murphy MM, Nolla H, Sha WC. ICOSinduced B7h shedding on B cells is inhibited by TLR7/8 and TLR9. J Immunol. (2006) 177:2356-64. doi: 10.4049/jimmunol.177.4. 2356

79. Watanabe M, Takagi Y, Kotani M, Hara Y, Inamine A, Hayashi K, et al. Downregulation of ICOS ligand by interaction with ICOS functions as a regulatory mechanism for immune responses. J Immunol. (2008) 180:5222-34. doi: 10.4049/jimmunol.180.8.5222

80. Lownik JC, Luker AJ, Damle SR, Cooley LF, El Sayed R, Hutloff A, et al. ADAM10-mediated ICOS ligand shedding on B cells is necessary for proper $\mathrm{T}$ cell ICOS regulation and T follicular helper responses. J Immunol. (2017) 199:2305-15. doi: 10.4049/jimmunol.1700833 
81. Wakamatsu E, Omori H, Ohtsuka S, Ogawa S, Green JM, Abe R. Regulatory $\mathrm{T}$ cell subsets are differentially dependent on $\mathrm{CD} 28$ for their proliferation. Mol Immunol. (2018) 101:92-101. doi: 10.1016/j.molimm.2018.05.021

82. Wakamatsu E, Omori H, Tabata Y, Akieda Y, Watanabe S, Ogawa S, et al. CD28 co-stimulation is dispensable for the steady state homeostasis of intestinal regulatory T cells. Int Immunol. (2018) 30:171-80. doi: 10.1093/ intimm/dxy013

83. Mikami N, Kawakami R, Chen KY, Sugimoto A, Ohkura N, Sakaguchi S. Epigenetic conversion of conventional $\mathrm{T}$ cells into regulatory $\mathrm{T}$ cells by CD28 signal deprivation. Proc Natl Acad Sci USA. (2020) 117:12258-68. doi: 10.1073/pnas.1922600117

84. Rowshanravan B, Halliday N, Sansom DM. CTLA-4: a moving target in immunotherapy. Blood. (2018) 131:58-67. doi: 10.1182/blood-2017-06741033

85. Tivol EA, Borriello F, Schweitzer AN, Lynch WP, Bluestone JA, Sharpe AH. Loss of CTLA-4 leads to massive lymphoproliferation and fatal multiorgan tissue destruction, revealing a critical negative regulatory role of CTLA-4. Immunity. (1995) 3:541-7.

86. Waterhouse P, Penninger JM, Timms E, Wakeham A, Shahinian A, Lee KP, et al. Lymphoproliferative disorders with early lethality in mice deficient in Ctla-4. Science. (1995) 270:985-8.

87. Wing K, Onishi Y, Prieto-Martin P, Yamaguchi T, Miyara M, Fehervari Z, et al. CTLA-4 control over Foxp3+ regulatory T cell function. Science. (2008) 322:271-5. doi: 10.1126/science.1160062

88. Shiratori T, Miyatake S, Ohno H, Nakaseko C, Isono K, Bonifacino JS, et al. Tyrosine phosphorylation controls internalization of CTLA- 4 by regulating its interaction with clathrin-associated adaptor complex AP-2. Immunity. (1997) 6:583-9.

89. Ovcinnikovs V, Ross EM, Petersone L, Edner NM, Heuts F, Ntavli E, et al. CTLA-4-mediated transendocytosis of costimulatory molecules primarily targets migratory dendritic cells. Sci Immunol. (2019) 4:eaaw0902. doi: 10. 1126/sciimmunol.aaw0902

90. Liakou CI, Kamat A, Tang DN, Chen H, Sun J, Troncoso P, et al. CTLA-4 blockade increases IFNgamma-producing CD4+ICOShi cells to shift the ratio of effector to regulatory $\mathrm{T}$ cells in cancer patients. Proc Natl Acad Sci USA. (2008) 105:14987-92. doi: 10.1073/pnas.08060 75105

91. Chen H, Liakou CI, Kamat A, Pettaway C, Ward JF, Tang DN, et al. Anti-CTLA-4 therapy results in higher CD4+ICOShi T cell frequency and IFN-gamma levels in both nonmalignant and malignant prostate tissues. Proc Natl Acad Sci USA. (2009) 106:2729-34. doi: 10.1073/pnas.0813 175106

92. Carthon BC, Wolchok JD, Yuan J, Kamat A, Ng Tang DS, Sun J, et al. Preoperative CTLA-4 blockade: tolerability and immune monitoring in the setting of a presurgical clinical trial. Clin Cancer Res. (2010) 16:2861-71. doi: 10.1158/1078-0432.ccr-10-0569

93. Ng Tang D, Shen Y, Sun J, Wen S, Wolchok JD, Yuan J, et al. Increased frequency of ICOS+ CD4 T cells as a pharmacodynamic biomarker for antiCTLA-4 therapy. Cancer Immunol Res. (2013) 1:229-34. doi: 10.1158/23266066.CIR-13-0020

94. Chen H, Fu T, Suh WK, Tsavachidou D, Wen S, Gao J, et al. CD4 T cells require ICOS-mediated PI3K signaling to increase T-Bet expression in the setting of anti-CTLA-4 therapy. Cancer Immunol Res. (2014) 2:167-76. doi: 10.1158/2326-6066.CIR-13-0155

95. Coutzac C, Adam J, Soularue E, Collins M, Racine A, Mussini C, et al. Colon immune-related adverse events: anti-CTLA- 4 and anti-PD- 1 blockade induce distinct immunopathological entities. J Crohns Colitis. (2017) 11:1238-46. doi: 10.1093/ecco-jcc/jjx081

96. Anderson MS, Bluestone JA. The NOD mouse: a model of immune dysregulation. Annu Rev Immunol. (2005) 23:447-85. doi: 10.1146/annurev. immunol.23.021704.115643

97. Tritt M, Sgouroudis E, d'Hennezel E, Albanese A, Piccirillo CA. Functional waning of naturally occurring $\mathrm{CD} 4+$ regulatory $\mathrm{T}$-cells contributes to the onset of autoimmune diabetes. Diabetes. (2008) 57:113-23. doi: 10.2337/ $\mathrm{db} 06-1700$

98. Brusko TM, Wasserfall CH, Clare-Salzler MJ, Schatz DA, Atkinson MA. Functional defects and the influence of age on the frequency of CD4+ CD25+ T-cells in type 1 diabetes. Diabetes. (2005) 54:1407-14. doi: 10.2337/diabetes. 54.5.1407
99. Brusko T, Wasserfall C, McGrail K, Schatz R, Viener HL, Schatz D, et al. No alterations in the frequency of FOXP3+ regulatory T-cells in type 1 diabetes. Diabetes. (2007) 56:604-12. doi: 10.2337/db06-1248

100. Herman AE, Freeman GJ, Mathis D, Benoist C. CD4+CD25+ T regulatory cells dependent on ICOS promote regulation of effector cells in the prediabetic lesion. J Exp Med. (2004) 199:1479-89. doi: 10.1084/jem. 20040179

101. Yamada Y, Okubo Y, Shimada A, Oikawa Y, Yamada S, Narumi S, et al. Acceleration of diabetes development in CXC chemokine receptor 3 (CXCR3)-deficient NOD mice. Diabetologia. (2012) 55:2238-45. doi: 10. 1007/s00125-012-2547-8

102. Tang Q, Adams JY, Penaranda C, Melli K, Piaggio E, Sgouroudis E, et al. Central role of defective interleukin-2 production in the triggering of islet autoimmune destruction. Immunity. (2008) 28:687-97. doi: 10.1016/j. immuni.2008.03.016

103. Grinberg-Bleyer Y, Baeyens A, You S, Elhage R, Fourcade G, Gregoire S, et al. IL-2 reverses established type 1 diabetes in NOD mice by a local effect on pancreatic regulatory T cells. J Exp Med. (2010) 207:1871-8. doi: 10.1084/ jem.20100209

104. Sgouroudis E, Kornete M, Piccirillo CA. IL- 2 production by dendritic cells promotes Foxp3(+) regulatory T-cell expansion in autoimmuneresistant NOD congenic mice. Autoimmunity. (2011) 44:406-14. doi: 10. 3109/08916934.2010.536795

105. Marek-Trzonkowska N, Mysliwiec M, Dobyszuk A, Grabowska M, Techmanska I, Juscinska J, et al. Administration of CD4+CD25highCD127regulatory $\mathrm{T}$ cells preserve $\beta$-cell function in type 1 diabetes in children. Diabetes Care. (2012) 35:1817-20. doi: 10.2337/dc12-0038

106. Marek-Trzonkowska N, Myśliwiec M, Dobyszuk A, Grabowska M, Derkowska I, Juścińska J, et al. Therapy of type 1 diabetes with CD4(+)CD25(high)CD127-regulatory T cells prolongs survival of pancreatic islets - results of one year follow-up. Clin Immunol. (2014) 153:23-30. doi: 10.1016/j.clim.2014.03.016

107. Tang Q, Henriksen KJ, Bi M, Finger EB, Szot G, Ye J, et al. In vitro-expanded antigen-specific regulatory $\mathrm{T}$ cells suppress autoimmune diabetes. J Exp Med. (2004) 199:1455-65. doi: 10.1084/jem.20040139

108. Masteller EL, Warner MR, Tang Q, Tarbell KV, McDevitt H, Bluestone JA. Expansion of functional endogenous antigen-specific CD4+CD25+ regulatory T cells from nonobese diabetic mice. J Immunol. (2005) 175:30539. doi: 10.4049/jimmunol.175.5.3053

109. Spence A, Purtha W, Tam J, Dong S, Kim Y, Ju C-H, et al. Revealing the specificity of regulatory T cells in murine autoimmune diabetes. Proc Natl Acad Sci USA. (2018) 115:5265-70. doi: 10.1073/pnas.1715590115

110. Visperas A, Vignali DAA. Are regulatory $\mathrm{T}$ cells defective in type 1 diabetes and can we fix them? J Immunol. (2016) 197:3762-70.

111. Mottet C, Uhlig HH, Powrie F. Cutting edge: cure of colitis by CD4+CD25+ regulatory T cells. J Immunol. (2003) 170:3939-43. doi: 10.4049/jimmunol. 170.8.3939

112. Coquerelle C, Oldenhove G, Acolty V, Denoeud J, Vansanten G, Verdebout JM, et al. Anti-CTLA-4 treatment induces IL-10-producing ICOS+ regulatory $\mathrm{T}$ cells displaying IDO-dependent anti-inflammatory properties in a mouse model of colitis. Gut. (2009) 58:1363-73. doi: 10.1136/gut.2008.162842

113. Tsai H-F, Wu C-S, Chen Y-L, Liao H-J, Chyuan IT, Hsu P-N. Galectin3 suppresses mucosal inflammation and reduces disease severity in experimental colitis. J Mol Med. (2016) 94:545-56. doi: 10.1007/s00109-0151368- $\mathrm{x}$

114. Tanoue T, Atarashi K, Honda K. Development and maintenance of intestinal regulatory T cells. Nat Rev Immunol. (2016) 16:295-309. doi: 10.1038/nri. 2016.36

115. Atarashi K, Tanoue T, Shima T, Imaoka A, Kuwahara T, Momose $\mathrm{Y}$, et al. Induction of colonic regulatory $\mathrm{T}$ cells by indigenous Clostridium species. Science. (2011) 331:337-41. doi: 10.1126/science.1198469

116. Atarashi K, Tanoue T, Oshima K, Suda W, Nagano Y, Nishikawa H, et al. Treg induction by a rationally selected mixture of Clostridia strains from the human microbiota. Nature. (2013) 500:232-6. doi: 10.1038/nature12331

117. Shao T-Y, Hsu L-H, Chien C-H, Chiang B-L. Novel Foxp3(-) IL-10(-) regulatory T-cells induced by B-cells alleviate intestinal inflammation in vivo. Sci Rep. (2016) 6:32415. doi: 10.1038/srep32415

118. Sato T, Kanai T, Watanabe M, Sakuraba A, Okamoto S, Nakai T, et al. Hyperexpression of inducible costimulator and its contribution on lamina 
propria T cells in inflammatory bowel disease. Gastroenterology. (2004) 126:829-39. doi: 10.1053/j.gastro.2003.12.011

119. Kanai T, Totsuka T, Tezuka K, Watanabe M. ICOS costimulation in inflammatory bowel disease. J Gastroenterol. (2002) 37(Suppl. 14):78-81. doi: 10.1007/BF03326419

120. Miao S, Xiong X. Detection and analysis of Tregs surface ICOS and CXCR3 in periphery blood of COPD patients. In Proceedings of the Poster Session Presented at: 2019-Annual Congress of Chinese Thoracic Society; 2019 Sep 04-08. Wuhan. (2019)

121. Akbari O, Freeman GJ, Meyer EH, Greenfield EA, Chang TT, Sharpe AH, et al. Antigen-specific regulatory T cells develop via the ICOS-ICOS-ligand pathway and inhibit allergen-induced airway hyperreactivity. Nat Med. (2002) 8:1024-32. doi: 10.1038/nm745

122. de Heer HJ, Hammad H, Soullié T, Hijdra D, Vos N, Willart MAM, et al. Essential role of lung plasmacytoid dendritic cells in preventing asthmatic reactions to harmless inhaled antigen. J Exp Med. (2004) 200:89-98. doi: 10.1084/jem.20040035

123. Han X, Wang S, Fan Y, Yang J, Jiao L, Qiu H, et al. Chlamydia infection induces ICOS ligand-expressing and IL-10-producing dendritic cells that can inhibit airway inflammation and mucus overproduction elicited by allergen challenge in BALB/c mice. J Immunol. (2006) 176:5232-9. doi: 10.4049/ jimmunol.176.9.5232

124. Shao Z, Bharadwaj AS, McGee HS, Makinde TO, Agrawal DK. Fms-like tyrosine kinase 3 ligand increases a lung DC subset with regulatory properties in allergic airway inflammation. J Allergy Clin Immunol. (2009) 123:91724.e2. doi: 10.1016/j.jaci.2009.01.052

125. McGee HS, Edwan JH, Agrawal DK. Flt3-L increases CD4+CD25+Foxp3+ICOS+ cells in the lungs of cockroach-sensitized and -challenged mice. Am J Respir Cell Mol Biol. (2010) 42:331-40. doi: 10.1165/rcmb.2008-0397OC

126. Maazi H, Patel N, Sankaranarayanan I, Suzuki Y, Rigas D, Soroosh P, et al. ICOS:ICOS-ligand interaction is required for type 2 innate lymphoid cell function, homeostasis, and induction of airway hyperreactivity. Immunity. (2015) 42:538-51. doi: 10.1016/j.immuni.2015.02.007

127. Rigas D, Lewis G, Aron JL, Wang B, Banie H, Sankaranarayanan I, et al. Type 2 innate lymphoid cell suppression by regulatory $\mathrm{T}$ cells attenuates airway hyperreactivity and requires inducible T-cell costimulator-inducible T-cell costimulator ligand interaction. J Allergy Clin Immunol. (2017) 139:146877.e2. doi: 10.1016/j.jaci.2016.08.034

128. Aron JL, Akbari O. Regulatory $\mathrm{T}$ cells and type 2 innate lymphoid celldependent asthma. Allergy. (2017) 72:1148-55. doi: 10.1111/all.13139

129. Whitehead GS, Wilson RH, Nakano K, Burch LH, Nakano H, Cook DN. IL-35 production by inducible costimulator (ICOS)-positive regulatory $\mathrm{T}$ cells reverses established IL-17-dependent allergic airways disease. $J$ Allergy Clin Immunol. (2012) 129:20715.e1-5. doi: 10.1016/j.jaci.2011. 08.009

130. Tesciuba AG, Subudhi S, Rother RP, Faas SJ, Frantz AM, Elliot D, et al. Inducible costimulator regulates Th2-mediated inflammation, but not Th2 differentiation, in a model of allergic airway disease. J Immunol. (2001) 167:1996-2003. doi: 10.4049/jimmunol.167.4.1996

131. Liu Y, Zhu T, Cai G, Qin Y, Wang W, Tang G, et al. Elevated circulating CD4+ ICOS+ Foxp3+ T cells contribute to overproduction of IL-10 and are correlated with disease severity in patients with systemic lupus erythematosus. Lupus. (2011) 20:620-7. doi: 10.1177/0961203310392431

132. Slauenwhite D, McAlpine SM, Hanly JG, Malik A, Haidl ID, Marshall JS, et al. Type 2 polarized $T$ cell phenotype is associated with methotrexate nonresponse in patients with rheumatoid arthritis. Arthritis Rheumatol. (2020) 72:1091-102. doi: 10.1002/art.41223

133. Sakthivel P, Grunewald J, Eklund A, Bruder D, Wahlström J. Pulmonary sarcoidosis is associated with high-level inducible costimulator (ICOS) expression on lung regulatory $\mathrm{T}$ cells-possible implications for the ICOS/ICOS-ligand axis in disease course and resolution. Clin Exp Immunol. (2016) 183:294-306. doi: 10.1111/cei. 12715

134. Strauss L, Bergmann C, Szczepanski MJ, Lang S, Kirkwood JM, Whiteside TL. Expression of ICOS on human melanoma-infiltrating CD4+CD25highFoxp3+ $\mathrm{T}$ regulatory cells: implications and impact on tumor-mediated immune suppression. J Immunol. (2008) 180:2967-80. doi: 10.4049/jimmunol.180.5.2967
135. Suzuki S, Ogawa T, Sano R, Takahara T, Inukai D, Akira S, et al. Immunecheckpoint molecules on regulatory T-cells as a potential therapeutic target in head and neck squamous cell cancers. Cancer Sci. (2020) 111:1943-57. doi: $10.1111 /$ cas.14422

136. Nagase H, Takeoka T, Urakawa S, Morimoto-Okazawa A, Kawashima A, Iwahori K, et al. ICOS Foxp3 TILs in gastric cancer are prognostic markers and effector regulatory $\mathrm{T}$ cells associated with Helicobacter pylori. Int $\mathrm{J}$ Cancer. (2017) 140:686-95. doi: 10.1002/ijc.30475

137. Faget J, Bendriss-Vermare N, Gobert M, Durand I, Olive D, Biota C, et al. ICOS-ligand expression on plasmacytoid dendritic cells supports breast cancer progression by promoting the accumulation of immunosuppressive CD4+ T cells. Cancer Res. (2012) 72:6130-41. doi: 10.1158/0008-5472.CAN12-2409

138. Toker A, Nguyen LT, Stone SC, Yang SYC, Katz SR, Shaw PA, et al. Regulatory $\mathrm{T}$ cells in ovarian cancer are characterized by a highly activated phenotype distinct from that in melanoma. Clin Cancer Res. (2018) 24:5685-96. doi: 10.1158/1078-0432.CCR-18-0554

139. Giraldo NA, Becht E, Vano Y, Petitprez F, Lacroix L, Validire P, et al. Tumorinfiltrating and peripheral blood T-cell immunophenotypes predict early relapse in localized clear cell renal cell carcinoma. Clin Cancer Res. (2017) 23:4416-28. doi: 10.1158/1078-0432.CCR-16-2848

140. Han Y, Dong Y, Yang Q, Xu W, Jiang S, Yu Z, et al. Acute myeloid leukemia cells express ICOS ligand to promote the expansion of regulatory $\mathrm{T}$ cells. Front Immunol. (2018) 9:2227. doi: 10.3389/fimmu.2018.02227

141. Sim GC, Martin-Orozco N, Jin L, Yang Y, Wu S, Washington E, et al. IL-2 therapy promotes suppressive ICOS+ Treg expansion in melanoma patients. J Clin Invest. (2014) 124:99-110. doi: 10.1172/JCI46266

142. Liu X, Yu H, Yan C, Mei Y, Lin C, Hong Y, et al. Plasmacytoid dendritic cells and ICOS regulatory $\mathrm{T}$ cells predict poor prognosis in gastric cancer: a pilot study. J Cancer. (2019) 10:6711-5. doi: 10.7150/jca.34826

143. Zhang Y, Luo Y, Qin S-L, Mu Y-F, Qi Y, Yu M-H, et al. The clinical impact of ICOS signal in colorectal cancer patients. Oncoimmunology. (2016) 5:e1141857. doi: 10.1080/2162402X.2016.1141857

144. Liu X, Wu S, Yang Y, Zhao M, Zhu G, Hou Z. The prognostic landscape of tumor-infiltrating immune cell and immunomodulators in lung cancer. Biomed Pharmacother. (2017) 95:55-61. doi: 10.1016/j.biopha.2017.08.003

145. Amatore F, Gorvel L, Olive D. Role of inducible co-stimulator (ICOS) in cancer immunotherapy. Expert Opin Biol Ther. (2019) 20:141-50.

146. Kymab Kymab Presents Data on Two of its Immuno-Oncology Antibodies, Providing Further Evidence of the Strength of its Franchise. (2020). Available online at: https://www.kymab.com/news-and-events/news/2018/ apr/18/ky1044-and-ky1055-results-2018-aacr/ (accessed June 17, 2020).

147. Guedan S, Posey AD, Shaw C, Wing A, Da T, Patel PR, et al. Enhancing CAR T cell persistence through ICOS and 4-1BB costimulation. JCI Insight. (2018) 3:e969761. doi: 10.1172/jci.insight.96976

148. Xiao Z, Mayer AT, Nobashi TW, Gambhir SS. ICOS is an indicator of T-cell-mediated response to cancer immunotherapy. Cancer Res. (2020) 80:3023-32. doi: 10.1158/0008-5472.CAN-19-3265

149. Sullivan BA, Tsuji W, Kivitz A, Peng J, Arnold GE, Boedigheimer MJ, et al. Inducible T-cell co-stimulator ligand (ICOSL) blockade leads to selective inhibition of anti-KLH IgG responses in subjects with systemic lupus erythematosus. Lupus Sci Med. (2016) 3:e000146. doi: 10.1136/lupus-2016000146

150. Cheng LE, Amoura Z, Cheah B, Hiepe F, Sullivan BA, Zhou L, et al. Brief report: a randomized, double-blind, parallel-group, placebo-controlled, multiple-dose study to evaluate AMG 557 in patients with systemic lupus erythematosus and active lupus arthritis. Arthritis Rheumatol. (2018) 70:1071-6. doi: 10.1002/art.40479

Conflict of Interest: The authors declare that the research was conducted in the absence of any commercial or financial relationships that could be construed as a potential conflict of interest.

Copyright $\odot 2020$ Li and Xiong. This is an open-access article distributed under the terms of the Creative Commons Attribution License (CC BY). The use, distribution or reproduction in other forums is permitted, provided the original author(s) and the copyright owner(s) are credited and that the original publication in this journal is cited, in accordance with accepted academic practice. No use, distribution or reproduction is permitted which does not comply with these terms. 